\title{
Appropriate Use Criteria for Nuclear Medicine in the Evaluation and Treatment of Differentiated Thyroid Cancer
}

\author{
Kevin J. Donohoe ${ }^{1}$, Jennifer Aloff ${ }^{2}$, Anca M. Avram ${ }^{3}$, K.G. Bennet ${ }^{3}$, Luca Giovanella ${ }^{4}$, Bennett Greenspan ${ }^{1}$, \\ Seza Gulec ${ }^{1}$, Aamna Hassan ${ }^{1}$, Richard T. Kloos ${ }^{5}$, Carmen C. Solórzano ${ }^{6}$, Brendan C. Stack, Jr. ${ }^{7}$, Mark Tulchinsky ${ }^{1}$, \\ Robert Michael Tuttle ${ }^{8}$, Douglas Van Nostrand ${ }^{1}$, and Jason A. Wexler ${ }^{9}$
}

\begin{abstract}
${ }^{1}$ Society of Nuclear Medicine and Molecular Imaging, Reston, Virginia; ${ }^{2}$ American Academy of Family Physicians, Washington, DC; ${ }^{3}$ American College of Nuclear Medicine, Reston, Virginia; ${ }^{4}$ European Association of Nuclear Medicine, Vienna, Austria; ${ }^{5}$ American Thyroid Association, Falls Church, Virginia; ${ }^{6}$ American Association of Endocrine Surgeons, Lexington, Kentucky; ${ }^{7}$ American Head and Neck Society, Los Angeles, California; ${ }^{8}$ American Association of Clinical Endocrinologists, Jacksonsville, Florida; and

${ }^{9}$ Endocrine Society, Washington, DC
\end{abstract}

\section{EXECUTIVE SUMMARY}

Nuclear medicine is an essential tool in the delivery of highquality medical care, going beyond simple anatomic imaging to the use of physiologic processes for both imaging and therapy. One of the first uses of nuclear medicine techniques occurred in the 1930s to demonstrate the physiology of radioiodine uptake by using the concentration of radioiodine in the thyroid, followed by the use of radioiodine for the treatment of hyperthyroidism and thyroid carcinoma in the 1940s. These investigations began a new era in the management of thyroid disease with nuclear imaging techniques and ${ }^{131}$ I radioiodine therapy (1). Although management has evolved since the 1940s, the basic principles have remained, including the use of radiopharmaceuticals to identify and localize disease, radioiodine ${ }^{123} \mathrm{I}$ and ${ }^{131} \mathrm{I}$ to test for iodine avidity, and radioiodine ${ }^{131} \mathrm{I}$ for radioiodine therapy.

These appropriate use criteria (AUC) (2) have been developed to describe the appropriate use of radiopharmaceuticals for diagnosis and therapy in patients with differentiated thyroid cancer (DTC). It is hoped that through these recommendations, nuclear medicine techniques will be used to benefit patients with DTC in the most cost-effective manner.

Representatives from the Society of Nuclear Medicine and Molecular Imaging (SNMMI), the European Association of Nuclear Medicine (EANM), the American Thyroid Association (ATA), the American Academy of Family Physicians (AAFP), the American College of Nuclear Medicine (ACNM), the American Association of Endocrine Surgeons (AAES), the American Association of Clinical Endocrinologists (AACE), the American Head and Neck Society (AHNS), and the Endocrine Society assembled as an autonomous workgroup to develop the following AUC (2). This process was performed in accordance with the Protecting Access to Medicare Act of 2014 (3). This legislation requires that all referring physicians consult AUC by using a clinical decision support (CDS) mechanism before ordering any advanced diagnostic imaging services.

Received Dec. 12, 2019; revision accepted Dec. 12, 2019.

For correspondence and reprints contact: Kevin Donohoe, Society of Nuclear Medicine and Molecular Imaging, 330 Brookline Ave., Boston, MA 02215.

Email: kdonohoe@caregroup.harvard.edu

COPYRIGHT (c) 2020 by the Society of Nuclear Medicine and Molecular Imaging. DOI: 10.2967/jnumed.119.240945
Such services are defined as diagnostic MRI, CT, and nuclear medicine procedures, including PET and others as specified by the Secretary of Health and Human Services in consultation with physician specialty organizations and other stakeholders (3).

The incidence of well-differentiated thyroid cancer (DTC) has been increasing worldwide. For example, it has increased by $4.4 \%$ per year from 2007 to 2011, and for the year 2017, the American Cancer Society estimates 56,870 new diagnoses and 2,010 thyroid cancer deaths occurring in the United States. Although considered a slow-growing malignancy with a generally good prognosis (5-y survival $99.9 \%$ for localized disease, $97.8 \%$ for regional metastatic disease), distant metastatic DTC is associated with a significantly worse prognosis (5-y survival 55.3\%, 10-y survival 26\%-38\%) (4-7).

Nuclear imaging of DTC is distinguished from conventional anatomic imaging by its ability to localize sites of radiotracer uptake and to quantify uptake at those sites, including at sites of metastatic disease. Radioiodines take advantage of the sodium iodide symporter-mediated uptake by most DTCs, which allows for characterization of disease as iodine avid (IA) versus noniodine avid (NIA), as well as the localization and quantification of IA remnant tissue in patients after thyroidectomy for DTC (7).

The following document describes the appropriate use of nuclear medicine scintigraphic imaging and ${ }^{131} \mathrm{I}$ therapy in patients with DTC. The most common clinical scenarios for scintigraphy and therapy in these patients are addressed. However, the reader is reminded that a patient may present with variations of the scenarios covered here, or with signs or symptoms not described, for which nuclear medicine techniques may still be indicated. This document is presented to assist health care practitioners in considering nuclear medicine imaging and therapy for patients with DTC; however, each patient is unique, as is each clinical presentation, and therefore this document cannot replace clinical judgment. Thyroid scintigraphy and ${ }^{131} \mathrm{I}$ therapy can also be used for nonmalignant thyroid diseases, for which assessment of iodine avidity and ${ }^{131} \mathrm{I}$ therapy is important for patient management. These other scenarios are beyond the scope of this document. Although many panel members felt that pretherapy diagnostic imaging is appropriate and helpful to confirm the presence, amount, and distribution of residual functioning thyroid tissue, especially in patients with risk of residual IA tissue, pretherapy imaging may not always be practical or necessary. 
These AUC will apply to all patients with DTC, including pediatric, adult, and older patients; males and females; and patients of all ethnic backgrounds. Special considerations may be given to the pediatric population, particularly when high-dosage ${ }^{131} \mathrm{I}$ therapy is considered, as this patient population has the potential to live many years after therapy. As with all treatment of neoplastic disease in the pediatric population, the consequences of therapy involving high-dose ionizing radiation must always be carefully weighed against alternative therapies and no therapy (8).

Although several long-term studies have described the accuracy and efficacy of nuclear medicine techniques for the management of DTC, rapid advances in imaging and therapy have made it difficult to thoroughly investigate all diagnostic and therapeutic clinical scenarios with well-designed clinical trials. Therefore, the Centers for Medicare and Medicaid Services (CMS) has recognized that expert opinion is often needed in the absence of evidence-based outcome literature. Where published outcome data are not available, the authors of this document have relied on expert opinion from nuclear medicine specialists in the United States and Europe and from referring practitioners. It is felt that by combining multispecialty expert opinion with the existing literature, the most accurate assessment possible can be made for the clinical utility of nuclear medicine techniques in the management of DTC. As new regulations take effect that require referring physicians to consult CDS tools before ordering diagnostic imaging and therapy for DTC, access to this important technology may become severely limited unless AUC are written for the inclusion of this test as an option in CDS tools.

Treatment of thyroid cancer with ${ }^{131} \mathrm{I}$ is helpful in many patients with high-risk disease; however, the benefits of ${ }^{131}$ I therapy in specific patient populations with low-risk disease is less clear (9). The reader is reminded that, as with diagnostic imaging of patients with DTC, patients may present for therapy with variations of the clinical scenarios described below. For all patients, the use of ${ }^{131}$ I therapy should be primarily guided by the informed decision of the individual patient in consultation with the treating physician whenever possible.

\section{METHODOLOGY}

\section{Workgroup Selection}

The experts of the AUC workgroup were convened by SNMMI to represent a multidisciplinary panel of health care providers with substantive knowledge of the diagnosis and treatment of DTC. In addition to nuclear medicine physicians who represented the SNMMI, physicians from the ATA, ACNM, AAFP, AAES, AHNS, AACE, Endocrine Society, and EANM were included in the workgroup. Fifteen physicians were ultimately selected as content experts to participate and contribute to the resulting AUC. A complete list of workgroup participants can be found in Appendix A. Appendix B is a summary of definitions of terms and acronyms, Appendix $C$ provides the disclosures and conflicts-of-interest statement, and Appendix D describes the solicitation of public commentary.

\section{AUC Development}

The process for AUC development was modeled after the RAND/UCLA Appropriateness Method $(10,11)$ and included the development of a list of common indications encountered in the management of patients with DTC, a systematic review of evidence related to these indications, and the development of an appropriateness score for each indication by using a modified Delphi process. This process strove to adhere to the standards of the Institute of Medicine of the National Academies for developing trustworthy clinical guidance (12). The process included a systematic synthesis of available evidence, individual and group ratings of the clinical indications by using a formal consensus process, and AUC recommendations based on final group ratings and discussions.

\section{Scope and Development of Clinical Indications}

To begin this process, the workgroup discussed various potential clinical indications for the postoperative imaging modalities for remnant, recurrent, or metastatic DTC and the effectiveness of postoperative treatment and diagnostic imaging in morbidity and mortality outcomes. For all indications, the relevant populations were patients with DTC of all genders, ages, races, and geographic locations, with subgroups of interest that included patients with radioactive iodine (RAI)-refractory cancers, pediatric/juvenile patients (18 y and under) with DTC, patients with metastatic thyroid cancer, pregnant patients, and breastfeeding patients.

The workgroup identified 42 clinical indications for patients with DTC. The indications are intended to represent the most relevant issues regarding the use of nuclear medicine in the diagnosis and management of DTC. The final appropriateness scoring for each clinical indication is based on evidence and expert opinion regarding the diagnostic accuracy and the effect on outcomes of the nuclear medicine technique described. Other factors affecting the AUC recommendations were potential harm, including long-term harm that may be difficult to capture, costs, availability, and patient preferences.

\section{Systematic Review}

To inform the workgroup, a systematic review of the relevant evidence was commissioned from an independent group, the Pacific Northwest Evidence-Based Practice Center of Oregon Health and Science University (OHSU) (13), to synthesize evidence on the diagnostic accuracy of postoperative imaging modalities for remnant, recurrent, or metastatic differentiated thyroid disease (DTC); the effectiveness of postoperative treatment and diagnostic imaging on morbidity and mortality outcomes; and the harms and cost-effectiveness of postoperative treatment with RAI. The workgroup selected the following key questions to guide the review:

1. In adult patients with DTC, what is the diagnostic accuracy of postoperative nuclear medicine imaging for remnant, recurrent, or metastatic disease?

2. In adult patients with DTC, what is the effectiveness of postoperative treatment with RAI $\left({ }^{131} \mathrm{I}\right)$ versus no ${ }^{131} \mathrm{I}$ on diseasefree, progression-free, disease-specific, or overall survival; quality of life; recurrence; or tumor response?

3. In adult patients with DTC, what is the effectiveness of postoperative diagnostic nuclear imaging versus no nuclear imaging on disease-free, progression-free, disease-specific, or overall survival; quality of life; recurrence; altered management; or tumor response (with or without SPECT or CT)?

4. In adult patients with DTC, what are the side effects of postoperative treatment with ${ }^{131} \mathrm{I}$ ?

5. In adult patients with DTC, what is the cost-effectiveness of postoperative treatment with ${ }^{131} \mathrm{I}$ ? 
The inclusion and exclusion criteria for papers for this review were based on the study parameters established by the workgroup, using the PICOTS (population, intervention, comparisons, outcomes, timing, and setting) approach. Searches for relevant studies and systematic reviews were conducted in the following databases: Cochrane Central Register of Controlled Trials, Cochrane Database of Systematic Reviews, and Ovid MEDLINE (through May 10, 2018). These searches were supplemented by reviewing the reference lists of relevant publications.

Two OHSU investigators independently assessed the quality (risk of bias) of each study as "good," "fair," or "poor" by using predefined criteria that were specific for each study design. Specifically, AMSTAR (A MeaSurement Tool to Assess systematic Reviews) was used for systematic reviews (except diagnostic accuracy), adapted by the US Preventive Services Task Force criteria for randomized trials and cohort studies, and QUADAS-2 (Quality Assessment of Diagnostic Accuracy Studies-2) for primary studies and systematic reviews of diagnostic accuracy $(14,15)$. Discrepancies were resolved through a consensus process. The strength of overall evidence was graded as high, moderate, low, or very low by using GRADE (Grading of Recommendations Assessment, Development and Evaluation) methods on the basis of quality of evidence, consistency, directness, precision, and reporting bias.

Database searches resulted in 2,964 potentially relevant articles. After dual review of abstracts and titles, 337 articles were selected for full-text dual review. Of these, 40 studies were determined to meet inclusion criteria and were included in this review. In addition, the expert panel also provided references that were not included in the results of the systematic review when those articles were felt to contribute to the evidence supporting the appropriateness rankings for the clinical indications.

\section{Rating and Scoring Process}

In developing these AUC for DTC, the workgroup members used the following definition of appropriateness to guide their considerations and group discussions: "The concept of appropriateness, as applied to health care, balances risk and benefit of a treatment, test, or procedure in the context of available resources for an individual patient with specific characteristics" (16).

At the beginning of the process, workgroup members convened at an in-person forum to develop the initial clinical indications. On evaluating the evidence summary of the systematic literature review, the workgroup further refined its draft clinical indications to ensure their accuracy and facilitate consistent interpretation when scoring each indication for appropriateness. Using the evidence summary, workgroup members were first asked individually to assess the appropriateness and provide a score for each clinical indication. Workgroup members then convened in a group setting for several successive webinars to discuss each indication and associated scores from the first round of individual scoring. After deliberate discussion, a consensus score was determined and then assigned to the associated appropriate use indication. For this scoring round, the expert panel was encouraged to include their clinical expertise in addition to the available evidence in determining the final scores. All members contributed to the final discussion, and no one was forced into consensus. After the rating process was completed, the final appropriate use ratings were summarized in a format similar to that outlined by the RAND/UCLA Appropriateness Method.

The workgroup scored each indication as "appropriate," "may be appropriate," or "rarely appropriate" on a scale from 1 to 9 . Scores 7-9 indicate that the use of the procedure is appropriate for the specific clinical indication and is generally considered acceptable. Scores 4-6 indicate that the use of the procedure may be appropriate for the specific indication. This implies that more research is needed to classify the indication definitively. Scores 1-3 indicate that the use of the procedure is rarely appropriate for the specific indication and is generally not considered acceptable.

As stated by other societies that develop AUC, the division of these scores into 3 general levels of appropriateness is partially arbitrary, and the numeric designations should be viewed as a continuum. In addition, if there was a difference in clinical opinion for an indication such that workgroup members could not agree on a common score, that indication was given a "may be appropriate" rating to indicate a lack of agreement on appropriateness based on the available literature and the members' collective clinical opinion.

\section{PLANAR AND TOMOGRAPHIC RADIOIODINE IMAGING IN DTC}

\section{Introduction}

Routine pretherapy RAI (17) scintigraphy is useful for completion of postoperative staging and accurate risk stratification of patients with thyroid cancer and has demonstrated a role in guiding ${ }^{131} \mathrm{I}$ therapy (18-20).

Detection of regional or distant metastases on pretherapy ablation scans may alter staging and risk stratification, hence changing the therapeutic RAI to be administered, either through adjustment of empiric ${ }^{131}$ I therapeutic dosages or performance of dosimetry calculations for treatment of distant metastatic disease (21-23).

\section{Background}

Accurate staging and assessment of risk are important for the management of thyroid cancer, as they determine the prognosis and guide therapeutic decisions and intensity of surveillance. Identification of regional and distant metastases on pretherapy diagnostic RAI scans is likely to alter management compared with that for standard ${ }^{131}$ I remnant ablation performed for elimination of normal thyroid tissue remnants. Visualization of metastatic deposits on radioiodine scans confirms their capacity to concentrate ${ }^{131}$ I (IA disease) and therefore the potential to respond to therapeutic ${ }^{131} \mathrm{I}$ activity; this permits adjustment of prescribed ${ }^{131} \mathrm{I}$ therapeutic activity for treatment of metastases compared with simple remnant ablation, which may be adequately achieved with lower activities. In patients with intermediate and high-risk disease and with diagnostic RAI scan findings of thyroid remnant tissue in the thyroidectomy bed, adjuvant ${ }^{131} \mathrm{I}$ treatment is recommended to irradiate and eliminate occult residual disease in the neck or other occult micrometastases, with the goal of improving recurrence-free survival $(24,25)$. (Refer to Appendix B for a more extensive discussion of risk terminology.)

Additional information obtained with pretherapy RAI scintigraphy may influence management decisions as follows: the discovery of unexpected bulky residual lymph nodal metastases in unexplored neck compartments may lead to surgical referral for reoperative neck dissection before ${ }^{131}$ I therapy; evidence of a large amount of residual thyroid tissue in the central neck may lead to referral for completion thyroidectomy before ${ }^{131}$ I therapy to minimize the risk of symptomatic radiation thyroiditis $(20,22)$.

The suspicion of NIA metastatic disease based on negative results of RAI scans in the context of elevated thyroglobulin ( $\mathrm{Tg}$ ) levels (or Tg levels out of proportion to the findings on the scan) may lead to additional imaging studies (neck ultrasound; neck/chest CT; ${ }^{18}$ F-FDG PET/CT) for localization of NIA disease. Finally, 
low-risk patients with undetectable Tg levels and negative results of RAI scans may need no ${ }^{131}$ I therapy.

Planar whole-body scintigraphy (WBS) with dedicated static images of the neck and chest are obtained at 1-2 d after oral ingestion of diagnostic activities of ${ }^{131} \mathrm{I}$ or ${ }^{123} \mathrm{I}$. Pinhole collimator imaging of the neck increases spatial image resolution and can be obtained for improved characterization of focal central neck activity (22).

Quantification of residual thyroid remnant tissue in the central neck is performed by obtaining neck RAI uptake (RAIU) measurements at $24 \mathrm{~h}$ after tracer RAI administration by using an uptake probe. This procedure provides information about the completeness of thyroid surgical resection, with an RAIU of $1 \%-2 \%$ being consistent with excellent resection and an RAIU of $<5 \%$ being considered adequate. RAIU at $24 \mathrm{~h}$ is, however, an integrative measure of RAI retention in the neck from thyroid remnant tissue or cervical nodal metastases. Therefore, RAIU measurement should be correlated with RAI scan information. SPECT/CT imaging has demonstrated improved anatomic localization of focal neck activity observed on planar RAI imaging and is helpful for distinguishing thyroid remnants from regional cervical nodal metastases (26-28).

Integration of information from surgical pathology, stimulated Tg levels, and scintigraphic imaging is necessary for individualization of RAI therapy. In a group of 320 patients with thyroid cancer referred for postoperative therapeutic ${ }^{131}$ I administration, diagnostic RAI scans with SPECT/CT imaging detected regional metastases in $35 \%$ of patients and distant metastases in $8 \%$ (19). Information acquired with diagnostic RAI scans changed staging in $4 \%$ of younger patients and $25 \%$ of older patients (19). Both imaging data and stimulated Tg levels acquired at the time of RAI scans were consequential for ${ }^{131}$ I therapy planning, providing information that changed risk stratification in $15 \%$ of patients and clinical management in $29 \%$ of patients compared with recurrence risk estimation and a management strategy based on clinical and surgical pathology information alone (18).

Posttherapy whole-body scans are routinely obtained $2-10 \mathrm{~d}$ after administration of therapeutic dosages of ${ }^{131} \mathrm{I}$ (29-31). The posttherapy scan may reveal additional foci of IA tissue compared with that from the diagnostic scan, affecting prognosis and subsequent management (32).
In the absence of a pretherapy diagnostic scan, many centers use posttherapy scans for diagnostic intent after standard remnant ablation. SPECT/CT imaging is considered an important diagnostic adjunct to planar imaging, with one study showing that it improved diagnostic interpretation compared with planar images alone in $44 \%$ of ${ }^{131} \mathrm{I}$ uptake foci, resulting in a change in management in $25 \%$ of patients (33).

One clear advantage of SPECT/CT is its ability to substantially reduce the number of equivocal foci seen on planar imaging alone. Chen et al. (34) reported that SPECT/CT accurately characterized $85 \%$ of foci considered inconclusive on planar imaging, resulting in altered management for $47 \%$ of patients.

After initial thyroidectomy and ${ }^{131}$ I therapy, follow-up imaging in 6-18 mo may be warranted in patients considered to be at risk for recurrence or in those where ablation of remnant tissue needs to be confirmed.

There is no universally agreed-on time for follow-up baseline or surveillance scanning after the initial diagnostic scan and the subsequent posttherapy scan. In patients with low-risk disease, there may be no need for further RAI imaging. In other patients, repeat RAI imaging is often considered at approximately 6 mo or longer after the prior scan.

\section{Clinical Scenarios and AUC Scores}

Clinical scenarios for the use of nuclear medicine and final AUC scores in planar and tomographic radioiodine imaging in thyroid cancer are presented in Table 1.

Scenario 1: Initial staging for Malignant IA Thyroid Tissue After Thyroidectomy (Score 9-Appropriate). After diagnosis of DTC and subsequent thyroidectomy, it is helpful to obtain a whole-body scan with radioiodine to determine the location and extent of IA thyroid tissue. This is particularly true in cases where tumors are classified as intermediate or high risk of recurrence on the basis of imaging and other characteristics. It is also especially important to detect regional or distant metastatic disease for more accurate staging. Staging with radioiodine may provide improved patient outcomes (35).

${ }^{131}$ I whole-body imaging provided relatively high accuracy that was slightly greater than that of ${ }^{18}$ F-FDG PET/CT $(36,37)$. Use of SPECT with ${ }^{131}$ I whole-body imaging provided slightly improved

TABLE 1

Clinical Scenarios for Planar and Tomographic Radioiodine Imaging in Thyroid Cancer (Diagnosis of DTC Already Established)

\begin{tabular}{|c|c|c|c|}
\hline Scenario no. & Description & Appropriateness & Score \\
\hline 1 & $\begin{array}{l}\text { Initial staging for malignant IA thyroid tissue } \\
\text { after thyroidectomy }\end{array}$ & Appropriate & 9 \\
\hline 2 & Assessing and quantifying residual IA remnant tissue & Appropriate & 9 \\
\hline 3 & $\begin{array}{l}\text { Posttherapy }{ }^{131} \text { I localization performed at } 2-10 \mathrm{~d} \text { after } \\
\text { radioiodine therapy }\end{array}$ & Appropriate & 9 \\
\hline 4 & $\begin{array}{l}\text { Inappropriately elevated } \mathrm{Tg} \text { (or elevated anti-TgAb) level } \\
\text { after thyroidectomy }\end{array}$ & Appropriate & 9 \\
\hline 5 & Follow-up/diagnostic/restaging evaluation scan & Appropriate & 8 \\
\hline 6 & $\begin{array}{l}\text { Follow-up/diagnostic/restaging evaluation scan with prior negative } \\
\text { results of }{ }^{131} \text { posttherapy images }\end{array}$ & May be appropriate & 5 \\
\hline 7 & $\begin{array}{l}\text { Follow-up/diagnostic/restaging evaluation scan to determine whether } \\
\text { structural lesion is IA }\end{array}$ & Appropriate & 9 \\
\hline 8 & Planar and tomographic radioiodine imaging in pregnant or lactating patients & Rarely appropriate & 1 \\
\hline
\end{tabular}


sensitivity with very high specificity. Sensitivity for lymph node metastases was relatively low (42\%), but sensitivity for lung metastases $(85 \%)$ and bone metastases $(87 \%)$ was relatively high. Additional radioiodine isotopes, such as ${ }^{123} \mathrm{I}$ (a pure $\gamma$-emitter) and ${ }^{124} \mathrm{I}$ (a positron emitter) have been used for thyroid cancer imaging. ${ }^{123} \mathrm{I}$ has been used as an alternative imaging agent to ${ }^{131} \mathrm{I}$ for diagnostic radioiodine scintigraphy because of its pure $\gamma$-emission ( $159 \mathrm{keV}$; physical half-life $13.3 \mathrm{~h}$ ) without the risk of iodine uptake "stunning" that has been attributed to ${ }^{131}$ I. Clinical experience with diagnostic ${ }^{123}$ I scans demonstrated their usefulness in thyroid cancer management: preablation ${ }^{123}$ I whole-body scans provided additional critical information in $25 \%$ of 122 patients by revealing unsuspected regional or distant metastases and thus guiding the administration of higher ${ }^{131} \mathrm{I}$ therapeutic activities, or revealing unexpected large thyroid remnants (21). In a cohort of 152 consecutive patients referred for postoperative ${ }^{131} \mathrm{I}$ ablative therapy at Stanford University, the information provided by diagnostic ${ }^{123}$ I whole-body scans led to a change in prescribed therapeutic ${ }^{131}$ I activity in $49 \%$ of cases compared with recommended ${ }^{131}$ I activities based on surgical pathology alone in the absence of ${ }^{123}$ I scintigraphy results (38).

SPECT/CT technology used in conjunction with diagnostic ${ }^{123}$ I whole-body scans provided increased specificity compared with that from classic planar scintigraphy: in a group of 79 consecutive patients studied with ${ }^{123} \mathrm{I}$ planar, SPECT, and SPECT/CT imaging, SPECT/CT provided additional diagnostic information in $42 \%$ of patients and further characterization in $70 \%$ of foci seen on planar images (39). In a group of 117 patients studied with planar WBS and SPECT/CT (of whom 108 underwent diagnostic ${ }^{123}$ I scans and 9 underwent posttherapy ${ }^{131}$ I scans), Spanu et al. (40) demonstrated that SPECT/CT had incremental value over planar imaging in $67.8 \%$ of patients, identified more foci of pathologic activity (158 foci on SPECT/CT compared with only 116 foci on planar), changed the treatment approach in $35.6 \%$ of patients with disease, and led to avoidance of unnecessary ${ }^{131}$ I therapy in $20 \%$ of patients without disease. Although an excellent radiotracer for thyroid imaging, ${ }^{123} \mathrm{I}$ is not as commonly used because of its higher cost, the large number of capsules required for adequate diagnostic ${ }^{123}$ I activity for whole-body scan imaging, the short physical half-life (which increases the complexity of dosimetry calculations), and the reported lesser sensitivity in detection of metastases compared with that of ${ }^{131} \mathrm{I}$ (41). Although ${ }^{123} \mathrm{I}$ is adequate for imaging of residual thyroid tissue in the neck, comparison of diagnostic ${ }^{123}$ I and ${ }^{131}$ I scans performed sequentially in the same patients demonstrated that ${ }^{123} \mathrm{I}$ is less sensitive than ${ }^{131} \mathrm{I}$ for detection of thyroid cancer metastases (41). In addition to these factors, the absence of evidence for stunning with low (1-2 mCi) diagnostic ${ }^{131} \mathrm{I}$ activities and when ${ }^{131} \mathrm{I}$ therapy is administered within $72 \mathrm{~h}$ of the diagnostic ${ }^{131} \mathrm{I}$ dose contributed to more widespread use of ${ }^{131} \mathrm{I}$ for diagnostic preablation scintigraphy (42-46). The decision about which radioisotope to use for diagnostic imaging should also include consideration of the timing between administration of the diagnostic tracer and the therapeutic tracer. A prolonged interval between the diagnostic tracer and the therapeutic tracer may result in a prolonged period of hypothyroidism or require additional doses of thyrotropin alfa (Thyrogen) to ensure proper concentration of the therapeutic dosage in the residual functioning thyroid tissue.

Stunning was defined as a reduction of ${ }^{131}$ I uptake seen on the posttherapy ${ }^{131} \mathrm{I}$ scan compared with that on the diagnostic ${ }^{131} \mathrm{I}$ scan. This interval reduction in iodine uptake was interpreted as being caused by the diagnostic dose and assumed to diminish the effect of the subsequent ${ }^{131}$ I therapy dose (47-49). However, other investigators who examined the issue have questioned this phenomenon, with studies demonstrating little or no evidence of stunning $(42,43,45,50,51)$. It is possible that stunning may be related to a true cytocidal effect of the high ${ }^{131}$ I diagnostic activities (5-10 $\left.\mathrm{mCi}{ }^{131} \mathrm{I}\right)$ used in the past $(44,52,53)$. Reduction of diagnostic ${ }^{131} \mathrm{I}$ activities to less than $2 \mathrm{mCi}$, along with technical improvements in instrumentation, image acquisition, and reconstruction protocols, has likely contributed to decreased stunning, leading to clinical implementation of a radiotheranostics paradigm for thyroid cancer management (54). A recent report that examined the results of a large SEER database $(28,220$ patients diagnosed with DTC between 1998 and 2011) demonstrates that postoperative diagnostic ${ }^{131}$ I whole-body imaging appears to provide information that leads to improved disease-specific survival in thyroid cancer (55).

Despite increased spatial resolution of PET/CT imaging, recombinant human thyroid-stimulating hormone (rhTSH) (Thyrogen)-stimulated ${ }^{124}$ I PET/CT scans were unable to predict positive results of ${ }^{131} \mathrm{I}$ posttherapy scans obtained after levothyroxine withdrawal in patients with metastatic DTC who presented with elevated serum $\mathrm{Tg}$ levels and negative results of diagnostic ${ }^{131} \mathrm{I}$ or ${ }^{123}$ I whole-body scans. The authors concluded that ${ }^{124}$ I PET scans have a low predictive value for negative results of post- ${ }^{131} \mathrm{I}$ therapy scans in patients with biochemical evidence of recurrent thyroid cancer and should not be used to exclude the option of blind ${ }^{131}$ I therapy in patients with negative results of radioiodine scintigraphy and elevation of $\mathrm{Tg}$ levels (56). However, ${ }^{124} \mathrm{I}$-sodium iodide (NaI) is not currently Food and Drug Administration (FDA) approved and therefore not reimbursable for thyroid cancer imaging in the United States. ${ }^{124} \mathrm{I}$ is a PET radiotracer that has also been used for lesion dosimetry studies in thyroid cancer (57-60).

Scenario 2: Assessing and Quantifying Residual IA Remnant Tissue (Score 9-Appropriate). After total thyroidectomy for treatment of thyroid cancer, a diagnostic radioiodine scan and neck uptake value at $24 \mathrm{~h}$ is performed by using either ${ }^{123} \mathrm{I}$ - or ${ }^{131} \mathrm{I}-\mathrm{NaI}$ to detect and quantify residual normal tissue remaining in the thyroidectomy bed and thyroglossal duct remnants after surgery. Accurate identification and localization of postsurgical RAI activity as thyroid remnant tissue versus lymph nodal metastatic disease can be greatly enhanced by SPECT/CT imaging $(18,19,23,28,61)$. Correlation of imaging findings with postoperative $\mathrm{Tg}$ levels and surgical histopathology is recommended for determining the objective of postoperative ${ }^{131} \mathrm{I}$ therapy. Remnant ablation, adjuvant treatment, or treatment of metastatic disease may be accomplished more effectively if all of the preceding factors are considered when determining the therapeutic ${ }^{131} \mathrm{I}$ activity to be administered. Neck RAIU at $24 \mathrm{~h}$ is used to quantify residual functional thyroid tissue in the neck after surgery. High residual uptake in the neck suggests that a repeat surgical procedure may be needed before RAI ablation.

Scenario 3: Posttherapy ${ }^{131}$ I localization Performed at 2-10 D After Radioiodine Therapy (Score 9 - Appropriate). As with pretherapy evaluation, posttherapy whole-body imaging of the distribution of the therapy dosage of ${ }^{131} \mathrm{I}$ is helpful in staging and managing disease burden $(33,62)$. The expert panel felt there was strong literature support for whole-body imaging of the therapeutic dosage of ${ }^{131} \mathrm{I}$.

Scenario 4: Inappropriately Elevated Tg (or Elevated Anti-Tg Antibody [Anti-TgAb]) Level After Thyroidectomy (Score 9 - Appropriate). $\mathrm{Tg}$ is a glycoprotein that is exclusively produced by the 
follicular cells of the thyroid gland and metabolized in the liver (63). Tg levels can therefore be used as a thyroid cancer biomarker, as they decline with a half-life $\left(t_{1 / 2}\right)$ of approximately $65 \mathrm{~h}$ after total thyroidectomy. Tg levels can become significantly elevated after surgery compared with preoperative values because surgical manipulation of the thyroid results in enhanced release of $\mathrm{Tg}$ into the circulation; it takes approximately $25 \mathrm{~d}$ after surgery for $\mathrm{Tg}$ levels to become a reliable marker of residual thyroid tissue or metastatic disease (64). TgAbs are a marker of thyroid autoimmunity and are detected in approximately $20 \%$ of patients with DTC. The presence of TgAb interferes with reliable measurement of $\mathrm{Tg}$, causing a falsely low/undetectable $\mathrm{Tg}$ level. Therefore, every serum specimen for $\mathrm{Tg}$ testing needs concomitant $\mathrm{TgAb}$ testing to indicate that the $\mathrm{Tg}$ measurement is not compromised by $\mathrm{TgAb}$ interference (65). Tg levels become undetectable in the absence of thyroid remnants and neoplastic disease after total thyroidectomy and RAI therapy. An increasing Tg level can therefore be used as an indicator of residual or recurrent DTC (66). Postoperative Tg levels cannot be used to define the likelihood of finding RAI-avid disease beyond the thyroid bed on the posttherapy scan, and a low/undetectable Tg level cannot exclude the presence of metastatic disease. In a recent study of 570 low-risk and low-intermediate-risk patients with DTC (pathologic staging classification [pTNM] pT1-pT3), posttherapy ${ }^{131}$ I scans with SPECT/CT demonstrated metastases in 82 patients $(14.4 \%)$, of whom $73(89 \%)$ had a postsurgical nonstimulated $\mathrm{Tg}$ level of $\leq$ $1 \mathrm{ng} / \mathrm{mL}$; stimulated Tg levels remained at $\leq 1 \mathrm{ng} / \mathrm{mL}$ in 44 patients $(54 \%)$, despite the presence of metastases on postherapy scans (67). Therefore, Tg levels of $<1 \mathrm{ng} / \mathrm{mL}$ cannot completely exclude the possibility of identifying metastatic uptake outside the thyroid bed. Notably, Tg may not be produced or secreted in thyroid cancer tumors with aggressive or poorly differentiated histology, and Tg values should always be interpreted while considering the clinical likelihood of disease.

Postoperative Tg levels are helpful in identifying high-risk patients who require higher ${ }^{131} \mathrm{I}$ activity but these levels cannot be used for ruling out postoperative ${ }^{131} \mathrm{I}$ therapy. The risk of persistent or recurrent disease increases as the postoperative $\mathrm{Tg}$ level rises, and several studies have demonstrated an increased risk of recurrence after total thyroidectomy and RAI remnant ablation in patients with postoperative nonstimulated Tg levels of $>0.1-0.2$ $\mathrm{ng} / \mathrm{mL}$ or stimulated Tg levels of $1-2 \mathrm{ng} / \mathrm{mL}(68,69)$. Rising nonstimulated $\mathrm{Tg}$ values are useful to identify patients with progressive disease (70). Suppressed or stimulated Tg levels of $>5-10$ $\mathrm{ng} / \mathrm{mL}$ increase the odds of detecting metastatic disease on imaging studies.
Finally, it is not clear what Tg level calls for empiric ${ }^{131}$ I therapy in those who have negative results on diagnostic RAI scans. Available data would suggest considering empiric RAI therapy (100-200 mCi) for those patients with Tg levels of $>10 \mathrm{ng} / \mathrm{mL}$ after levothyroxine withdrawal or $>5 \mathrm{ng} / \mathrm{mL}$ after $\mathrm{rhTSH}$ stimulation (71). This approach has been shown to localize disease activity in about half of patients (72). Half of patients will see a fall in Tg levels over time, but there is no evidence to support an improvement in survival with this approach. Advances in molecular diagnostic imaging and the clinical availability of ${ }^{18} \mathrm{~F}-\mathrm{FDG}$ PET/CT produced a paradigm shift in the management of thyroid cancer by allowing improved characterization of tumor biology. For patients with negative results of ${ }^{131} \mathrm{I}$ scans and elevated $\mathrm{Tg}$ levels, it is important to consider alternative imaging with ${ }^{18} \mathrm{~F}$ FDG PET/CT for localization of NIA metastatic disease (see Table 2) (73).

Clinical utility of serum $\mathrm{Tg}$ measurement may be limited by the presence of $\operatorname{TgAb}$ or heterophile antibodies and by interassay variability in measured $\mathrm{Tg}$. It is critical to retain the same method for long-term $\mathrm{Tg}$ and $\mathrm{TgAb}$ monitoring. When present, $\mathrm{TgAb}$ concentrations can be monitored as a surrogate tumor marker for DTC (65). Management of TgAb-positive patients requires a specific approach (see scenario 5 below). For these reasons, the expert panel felt that radioiodine imaging was appropriate in patients with elevated $\mathrm{Tg}$ or $\mathrm{TgAb}$ levels.

Scenario 5: Follow-up/Diagnostic/Restaging Evaluation Scan (Score 8-Appropriate). Any single therapeutic dosage of ${ }^{131} \mathrm{I}$ may not ablate all functioning residual tissue in the thyroid bed or in all functioning metastases. As with initial staging, if an additional therapeutic dosage of ${ }^{131} \mathrm{I}$ is being considered, a restaging evaluation with diagnostic dosages of radioiodine can be helpful for restaging and for determination of dosage for therapeutic ${ }^{131}$ I administration. Epidemiological studies suggest that the use of diagnostic imaging has been on the rise, particularly ultrasound; however, ultrasound was shown to be strongly associated with increased use of biopsy and surgical interventions that had no downstream improvement in disease-specific survival. A diagnostic RAI whole-body scan for restaging evaluation was the only test performed after initial RAI therapy that was associated with improvement in disease-specific survival of patients with DTC (55).

Scenario 6: Follow-up/Diagnostic/Restaging Evaluation Scan with Prior Negative Findings on ${ }^{131}$ I Posttherapy Images (Score 5 May Be Appropriate). Radioiodines are taken up by most DTCs, allowing for characterization of disease as IA versus NIA, as well as localization and quantification of IA remnant tissue in patients

TABLE 2

Clinical Scenarios for ${ }^{18} \mathrm{~F}-\mathrm{FDG}$ Imaging in DTC

\begin{tabular}{|c|c|c|c|}
\hline Scenario no. & Description & Appropriateness & Score \\
\hline 1 & $\begin{array}{l}\text { Evaluation for thyroid cancer with detectable } \mathrm{Tg} \text { (or elevated anti-TgAb) } \\
\text { level and negative findings on radioiodine scan }\end{array}$ & Appropriate & 8 \\
\hline 2 & $\begin{array}{l}\text { Suspected }{ }^{18} \mathrm{~F}-\mathrm{FDG} \text {-avid thyroid cancer in patients after total or near- } \\
\text { total thyroidectomy }\end{array}$ & Appropriate & 8 \\
\hline 3 & Established thyroid cancer in patients before thyroidectomy & May be appropriate & 4 \\
\hline 4 & $\begin{array}{l}\text { Established }{ }^{18} \mathrm{~F}-\mathrm{FDG} \text {-avid thyroid cancer in patients after } \\
\text { thyroidectomy }\end{array}$ & Appropriate & 8 \\
\hline 5 & Pregnant or lactating patients & Rarely appropriate & 1 \\
\hline
\end{tabular}


after thyroidectomy (37). RAIU in metastatic disease may be depressed by several factors, including loss of the iodide symporter (dedifferentiated cancer) and poor preparation for imaging or inadequate imaging technique (74). Knowledge of IA is important for prognosis and treatment decisions for patients with DTC. Patients who received prior RAI therapy and had negative results of a ${ }^{131}$ I posttherapy scan may still be candidates for follow-up RAI diagnostic scanning to evaluate IA (75). Such patients may have rising Tg levels or a new structural lesion. A diagnostic/ restaging RAI scan can help confirm lack of iodine avidity or can demonstrate new disease that is IA. In addition, if there is substantial belief that prior treatment or imaging was inadequate or inaccurate, leading to a false-negative posttreatment scan (76), a repeat RAI scan may be justified.

Scenario 7: Follow-up/Diagnostic/Restaging Evaluation Scan to Determine Whether Structural Lesion Is IA (Score 9 - Appropriate). One of the primary roles of RAI scanning in follow-up and diagnostic/restaging evaluations is to determine whether a structural lesion is IA. Five studies have evaluated the diagnostic accuracy of ${ }^{131} \mathrm{I}$ whole-body scans for the detection of metastatic thyroid cancer $(36,37,77-79)$. Sensitivity for detection of distant metastasis ranged from $61 \%$ to $93 \%$ across studies $(36,37,77-79)$. Differences in sensitivity are likely related to tumor histology, volume of metastatic disease, Tg levels, patient preparation, and imaging technique. Specificity was improved when imaging was done with SPECT/CT (37).

${ }^{123} \mathrm{I}$ and ${ }^{124} \mathrm{I}$ are potential alternatives to ${ }^{131} \mathrm{I}$ whole-body scanning, although they are more expensive $\left({ }^{123} \mathrm{I}\right.$ and $\left.{ }^{124} \mathrm{I}\right)$ and less readily available $\left({ }^{124} \mathrm{I}\right)$ than ${ }^{131} \mathrm{I}$. The data on the sensitivity of ${ }^{123} \mathrm{I}$ compared with ${ }^{131} \mathrm{I}$ are limited. However, one study described a sensitivity of $75 \%$ by using ${ }^{123}$ I scanning to detect metastatic disease (80). With regard to ${ }^{124} \mathrm{I}$ diagnostic imaging, a recent metaanalysis described $94.2 \%$ sensitivity in detecting metastatic lesions amenable to ${ }^{131}$ I therapy (81).

Thus, RAI diagnostic scanning, with either ${ }^{131} \mathrm{I},{ }^{123} \mathrm{I}$, or ${ }^{124} \mathrm{I}$, can identify RAI-avid structural metastatic disease with clinically relevant sensitivity and specificity.

Scenario 8: Planar and Tomographic Radioiodine Imaging in Pregnant or Lactating Patients (Score 1 - Rarely Appropriate). Pregnancy is a contraindication to radioiodine administration. The radiation dose to the embryo/fetus can cause miscarriage, birth defects, cretinism, and an increase in childhood malignancies. RAI administration while lactating is also contraindicated. Radioactive iodide is concentrated in the milk and can be delivered to the infant through ingestion of the milk, leading to irradiation of the infant's thyroid. To mitigate the radiation dose to the female breast and infant, breastfeeding should be stopped at least 4 (preferably 6) wk before administration of radioiodine and should not be restarted after administration of RAI. Breastfeeding can, however, be resumed with future pregnancies (82).

\section{Summary of Recommendations}

Whole-body radioiodine imaging with planar imaging (and SPECT/CT, if needed) is an essential tool for the management of patients with thyroid cancer after thyroidectomy. $\mathrm{Tg}$ and $\mathrm{TgAb}$ levels may assist in the decision to use radioiodine imaging, but they are not sensitive and specific enough to be the sole determining factor of which patients should or should not receive whole-body radioiodine imaging. Whole-body imaging provides unique information that can assist with patient management when acquired both before and after radioiodine therapy.
While some centers ablate remnant thyroid tissue with a standard postthyroidectomy dosage of ${ }^{131} \mathrm{I}$, many practitioners use imaging with diagnostic dosages of radioiodine before ${ }^{131} \mathrm{I}$ therapy dosages to tailor the ${ }^{131}$ I therapy dosage to the amount of remnant tissue and the number and location of metastatic lesions, if present. It is felt by the expert panel that tailoring the ${ }^{131}$ I treatment dosage may prevent radiation toxicity in the neck in the event of a large remnant, while allowing more effective treatment of metastatic lesions.

\section{RAI DOSIMETRY}

\section{Introduction}

There are 3 broad approaches to ${ }^{131}$ I treatment: (1) empiric dosages (based on convention, experience, and patient-related factors), (2) maximum permissible dose (determined by the upper bound limit of whole-body blood [bone marrow] dosimetry [WBBD]), and (3) target/lesion dosimetry. ${ }^{131} \mathrm{I}$ treatment is contraindicated in pregnant or lactating patients. Empirically chosen ${ }^{131} \mathrm{I}$ treatment dosage poses a greater risk of undertreating the targeted tissue or exceeding safety limits (83).

\section{Selecting Therapeutic ${ }^{131}$ I Activities}

Dosimetric approaches focus on the radiation dose delivered to the body and target tissue, rather than on the activity administered (84). RAI treatment for DTC is almost always appropriate only after thyroidectomy. Dosimetry can be used to calculate the administered activity needed to ablate the remnant thyroid tissue after total, near-total, or subtotal thyroidectomy. A completion thyroidectomy should be considered if the initial surgical treatment is a lobectomy. WBBD determines the maximum tolerable activity (MTA) on the basis of the radiation dose to the normal tissues, particularly tissues at risk, such as bone marrow and lungs. Lesional dosimetry determines the radiation dose to the target tissues (thyroid remnant or metastases). The combination of lesional dosimetry with WBBD determines whether an adequate therapeutic dose can be delivered to target tissues while not exceeding the MTA. Retrospective studies (with significant methodologic limitations) have investigated empiric activities compared with WBBD calculation in the setting of distant metastases or locoregionally advanced disease and have failed to demonstrate the superiority of one method over the other to improve overall survival or progression-free survival $(85,86)$. In the absence of prospective randomized clinical trials, the selection of dosage for ${ }^{131} \mathrm{I}$ treatment and the conclusions that can be drawn from available retrospective studies remain highly controversial $(25,86-90)$.

Dosimetric calculation is a sophisticated nuclear medicine procedure requiring a nuclear medicine department with a team of committed physicians, technologists, and physicists. However, several dosimetry protocols can be adapted to routine clinical use. Currently, dosimetry is most commonly performed in medical centers with dedicated thyroid cancer programs. Dosimetry is more likely to be of benefit for patients with known distant metastases or unusual cases such as when renal failure is present.

\section{Maximum Safety Limit of the ${ }^{131}$ I Activity Established by Dosimetry}

Early observations suggested that metastatic DTCs treated with repeated small dosages of ${ }^{131} \mathrm{I}$ tended to continue to grow but lose the ability to concentrate ${ }^{131} \mathrm{I}(91)$. Thus, in 1949 , researchers focused on treating metastatic differentiated thyroid carcinoma with the largest safe dose on the basis of dosimetric formulations proposed by Benua et al. (91). (The Society of Nuclear Medicine 
later developed a standardized system, currently in use, called MIRD methodology.) Patients received individual ${ }^{131} \mathrm{I}$ activities of radioiodine ranging from 6 to $600 \mathrm{mCi}$ and delivering $0.45-$ 7.4 Gy to bone marrow. Serious complications were more frequent when the dose to the blood exceeded $2 \mathrm{~Gy}$, more than $300 \mathrm{mCi}$ of ${ }^{131} \mathrm{I}$ was administered, or more than $120 \mathrm{mCi}$ of ${ }^{131} \mathrm{I}$ was retained in the body $48 \mathrm{~h}$ after treatment. The current most commonly accepted maximum therapeutic activity delivers a maximum of 2 Gy to the blood while keeping whole-body retention at less than $120 \mathrm{mCi}$ at $48 \mathrm{~h}$, or less than $80 \mathrm{mCi}$ at $48 \mathrm{~h}$ when there is diffuse pulmonary uptake (92-94). The WBBD approach identifies the MTA, or the activity considered as high as safely achievable (AHASA) (87). Severe complications from these large therapies are infrequent $(25,95)$ but not absent $(91,96)$. Complete $(87,97)$ and simplified protocols have been published (85).

\section{Lesional (Remnant or Tumor) Dosimetry}

The purpose of lesional dosimetry is to provide enough ${ }^{131} \mathrm{I}$ activity for effective radiation-absorbed dose in the lesion, while avoiding excess dose in normal tissues. The absorbed dose needed for remnant ablation is dependent on the dosimetry methodology applied (98-102).

The clinical feasibility of remnant and tumor dosimetry has been demonstrated in several studies $(86,88,97,99,100,103)$. The mass of tissue and the effective half-time of ${ }^{131} \mathrm{I}$ in the tissue are required for basic dosimetric computations. Volume measurements are more reliable for discrete nodal lesions. Dosimetry is challenging for remnant tissue and thyroid bed recurrences because the contour and nondiscrete nature of these lesions make determination of tissue volume difficult. In one study, lymph node metastases were treated successfully in $74 \%$ of patients with a single administration of ${ }^{131}$ I calculated to deliver at least 85 Gy. For patients with uptake in nodal metastases only, and no uptake in other metastases or the thyroid bed, success was achieved in $86 \%$ of patients at tumor doses of at least 140 Gy (100). In each scenario, the dose stated was the lowest dose achieved, and there was no trend toward greater success with higher radiation doses. Lesions calculated to receive less than 30-40 Gy despite reaching the MTA may be considered as alternative therapy. A wide range of absorbed doses to targets can be seen in individual patients, and inhomogeneous absorbed dose distributions can be seen within an individual lesion (89). Diffuse pulmonary micrometastases are treated according to the WBBD method described above.

Current state-of-the-art lesion dosimetry can include radioiodine theranostics, using the advantage of improved spatial resolution of ${ }^{124}$ I PET/CT to quantify target volume; in vivo tumor concentration; and radionuclide biodistribution $(98,101,102)$.
Complete and simplified ${ }^{124}$ I radioiodine PET/CT dosimetry protocols have been developed for clinical applications (104).

\section{Clinical Scenarios and AUC Scores}

Clinical scenarios and final AUC scores for the use of RAI dosimetry in patients with DTC are presented in Table 3.

Scenario 1: Determination of Prescribed Activity for ${ }^{131}$ I Treatment After Thyroidectomy (Score 7 - Appropriate). After total or near-total thyroidectomy, one of several dosimetric approaches can be used to calculate therapeutic dosage for thyroid remnant ablation, adjuvant treatment, or treatment of thyroid cancer. Compared with empirically determined activities, high-level evidence does not exist to favor either empiric or dosimetric methods; however, the expert panel felt that dosimetric calculations may be beneficial and therefore may be used in centers that are skilled in radioiodine dosimetry.

Scenario 2: Determination of Prescribed Activity for ${ }^{131}$ I Treatment in Patients Before Thyroidectomy (Score 1 - Rarely Appropriate). Dosimetry to calculate RAI activities to destroy normal or malignant tissue is rarely appropriate until nearly all normal thyroid tissue has been surgically removed. While comparison of surgical and radioiodine thyroidectomy has not been published, the expert panel felt that surgical resection is a more definitive management in patients with thyroid cancer.

Scenario 3: Pregnant or Lactating Patients (Score 1 - Rarely Appropriate). Pregnancy is a contraindication to radioiodine administration. The radiation dose to the embryo/fetus can cause miscarriage, birth defects, cretinism, and an increase in childhood malignancies. RAI administration to lactating women is also contraindicated. Radioactive iodide is concentrated in the milk and can be delivered to the infant through ingestion of the milk, leading to irradiation of the infant's thyroid. To mitigate the radiation dose to the female breast and infant, breastfeeding should be stopped at least 4 (preferably 6) wk before administration of radioiodine and should not be restarted after administration of RAI (82). Lactation can be safely done with future pregnancies.

\section{Summary of Recommendations}

Controversies continue regarding the method used to determine the dosage of ${ }^{131}$ I used to treat suspected or known metastatic DTC. The 2 main approaches are empirically based treatment and dosimetrically based treatment. The empiric approach draws on the experience of one or more individuals, whereas the dosimetric approach is based on direct measurement of the radioiodine radiation dose to the tissues. These direct measurements help determine the dosage of ${ }^{131}$ I needed to treat a metastasis successfully without exceeding a dosage that will result in unacceptable side effects. Although many different empirically based and dosimetrically

TABLE 3

Clinical Scenarios for RAI Dosimetry

\begin{tabular}{llc}
\hline Scenario no. & Description & Appropriateness \\
\hline 1 & $\begin{array}{c}\text { Determination of prescribed activity for }{ }^{131} \text { I treatment after } \\
\text { thyroidectomy } \\
\text { Determination of prescribed activity for }{ }^{131} \text { | treatment in patients } \\
\text { before thyroidectomy } \\
\text { RAl dosimetry in pregnant or lactating patients }\left({ }^{123} \text { vs. }{ }^{131} \text { in }\right. \\
\text { indication section of text) }\end{array}$ & Appropriate \\
\hline 3 & Rarely appropriate \\
\hline
\end{tabular}


based methods have been used for over $60 \mathrm{y}$, no well-designed prospective study has compared these 2 approaches. Some individuals have argued that until such a prospective study is performed, one should only use an empiric approach; others have argued that until such a study is performed, one should only use a method that is based in the dosimetric fundamentals of radiation therapy. At this time, the consensus of this committee is that both approaches can be appropriate, and the approach chosen will depend on factors such as the clinical scenario, the facilities available, the expertise available, and the physician and patient desires regarding benefits versus risk. However, the writing committee of these AUC felt a well-designed prospective study that compares approaches to radioiodine therapy should be pursued.

\section{RAIU IN THE NECK/THYROID BED}

\section{Introduction}

The amount of administered diagnostic radioactive iodide accumulated in remnant thyroid at $24 \mathrm{~h}$ or later is a common part of the postthyroidectomy evaluation in the management of patients with DTC. It is traditionally termed the RAIU. The RAIU most commonly reflects the amount (i.e., the volume) of the remnant functioning benign thyroid (RFBT) tissue. While remnant DTC tissue could contribute to the RAIU in the neck, such uptake would be negligible compared with the RFBT at the first assessment after thyroidectomy. This is because of (1) inherently lower avidity in remnant DTC compared with that in RFBT and (2) typically complete surgical removal of all DTC from the thyroid bed.

\section{Background}

The measurement of RAIU in the postsurgical thyroid bed is a routine procedure that is performed by using either an uptake probe or an image acquired with a $\gamma$-camera. The latter approach uses regions of interest to outline the thyroid bed, excluding pathologic and other activity, and corrects for background activity. There is wide methodologic variability in RAIU measurement; despite this variability, there are several clinically useful applications. The postthyroidectomy RAIU for individual patients varies broadly depending on the experience of the surgeon as defined by annual case volume (105). In fact, it was suggested that it can be used as a quantitative quality indicator for the total thyroidectomy surgical procedure (105). Higher RFBT uptake was suggested to be associated with higher risk of DTC recurrence (105). Higher RAIU in the thyroid bed leads to higher deposited therapeutic activity, which correlates with a greater chance of symptomatic radiation thyroiditis (106).

\section{Clinical Scenarios and AUC Scores}

Clinical scenarios for the use of nuclear medicine in the quantification of postoperative residual functioning thyroid tissue in the neck and final AUC scores are presented in Table 4.

Scenario 1: Quantification of Remnant Tissue After Thyroidectomy (Score 8 - Appropriate). RAIU is a surrogate for the posttotal thyroidectomy RFBT volume (107). A preparation/techniquedependent (i.e., institution-specific) algorithm can be established to allow for calculation of a maximum $\mathrm{Tg}$ cutoff value produced by a benign remnant, based on the percentage of RAIU at 24 or $48 \mathrm{~h}$ (108). Tg levels below the cutoff value would suggest no remaining DTC, supporting ablation of the thyroid remnant as the goal of initial ${ }^{131} \mathrm{I}$ treatment. If the Tg level is above the RAIU cutoff value, concern for metastatic DTC may be justified. If the whole-body RAI scan with SPECT/CT of the neck are unrevealing in these cases, escalating the goal of therapy to adjuvant treatment may be warranted.

RAIU in posttotal thyroidectomy patients also correlates with the likelihood of symptomatic radiation thyroiditis. Higher RAIU is more commonly associated with symptomatic thyroiditis after ${ }^{131}$ I therapy $(106,108)$. The administered activity may need to be decreased in patients with high RAIU. The chance of painful thyroiditis is only $12 \%$ for $37 \mathrm{MBq}(1 \mathrm{mCi})$ delivered to the thyroid bed, based on RAIU measurement. The risk of symptoms increased by $64 \%$ for each additional $37 \mathrm{MBq}$ deposited in the thyroid bed based on the RAIU. Severe thyroiditis was observed only in those receiving $>73 \mathrm{MBq}$ to the thyroid bed.

Scenario 2: RAIU in the Neck/Thyroid Bed in Pregnant or Lactating Patients (Score 1 - Rarely Appropriate). Pregnancy is a contraindication to radioiodine therapy. The radiation dose to the embryo/fetus can cause miscarriage, birth defects, cretinism, and an increase in childhood malignancies. RAI administration while lactating is also contraindicated. Radioactive iodide is concentrated in the milk and can be delivered to the infant through ingestion of the milk, leading to irradiation of the infant's thyroid. To mitigate the radiation dose to the female breast and infant, breastfeeding should be stopped at least 4 (preferably 6) wk before administration of radioiodine and should not be restarted after administration of RAI (82). Lactation can be safely done with future pregnancies.

\section{Summary of Recommendations}

Radioiodine uptake is a standard technique for measuring ${ }^{131} \mathrm{I}$ in the postoperative thyroid bed. This measure is a surrogate for the RFBT tissue volume in postthyroidectomy patients and allows for estimation of the maximal $\mathrm{Tg}$ level that could be attributable to benign remnant tissue. The information can be used for a logical selection of the goal of therapy (ablation vs. adjuvant). The risk of symptomatic radiation thyroiditis may also be predicted from RAIU in the surgical bed, helping to inform and manage patients. Radioiodine uptake measurement and radioiodine therapy are to be avoided in pregnant and lactating patients.

\section{I THERAPY FOR DTC IN PATIENTS WHO HAVE HAD TOTAL OR NEAR-TOTAL THYROIDECTOMY}

\section{Introduction}

${ }^{131} \mathrm{I}$ is an effective and well-established therapeutic option for DTC after thyroidectomy has been performed. The 13 clinical

TABLE 4

Clinical Scenarios for RAIU

\begin{tabular}{lll}
\hline Scenario no. & Description & Appropriateness \\
\hline 1 & Quantification of remnant tissue after thyroidectomy & Appropriate \\
2 & RAIU in the neck/thyroid bed in pregnant or lactating patients & Rarely appropriate \\
\hline
\end{tabular}


scenarios that follow in this section, while not exhaustive, are felt to be the most common scenarios that may be encountered in patients with DTC after thyroidectomy. Many of the clinical scenarios that the expert panel considered in this section were not ranked as an appropriate use of ${ }^{131}$ I therapy; however, the panel felt it was important to propose and discuss as many clinical scenarios as possible in which ${ }^{131}$ I therapy may be considered, so that practitioners would have both guidance in favor of ${ }^{131} \mathrm{I}$ therapy, when it is felt to be appropriate, and a discussion of when ${ }^{131}$ I therapy is less well supported.

\section{Background}

RAI therapy among patients with DTC is considered for the ablation of residual thyroid remnant tissue, suspected residual cancer (adjuvant therapy), and known residual cancer (treatment). Its use is typically considered after optimal resection of the primary tumor with total thyroidectomy and local-regional disease resection (25). RAI therapy is rarely considered after primary tumor resection with a thyroid lobectomy $(24,109)$ and almost never considered before addressing the primary tumor and normal thyroid tissue with surgery. Because of radiation risks to the fetus and lactating breast, RAI therapy is contraindicated in the settings of pregnancy and breastfeeding. A 4- to 6-wk interval after cessation of breastfeeding is typically recommended before ${ }^{131}$ I therapy to decrease radiation dose to the breast (and infant). It is typically not possible to resume breastfeeding after its cessation for such an extended period, and therefore patients should be counseled as such. Breast uptake of radioiodine should be evaluated during diagnostic radioiodine imaging before therapy, particularly in patients who have been breastfeeding in the past 3-6 mo (25).

The ATA advocates postsurgical ${ }^{131}$ I therapy in patients with DTC at ATA high risk of recurrence after total thyroidectomy and against its use in patients at ATA low risk with tumors of $\leq 1 \mathrm{~cm}$ confined to the thyroid (unifocal or multifocal), on the basis of studies of ${ }^{131}$ I therapy impact on disease-specific survival or disease-free survival (25). ${ }^{131}$ I remnant ablation is not routinely recommended for the remaining patients at ATA low risk after lobectomy or total thyroidectomy, whereas ${ }^{131}$ I adjuvant therapy is considered after total thyroidectomy in patients with an intermediate risk of recurrence (25). Similar recommendations are advocated by the National Comprehensive Cancer Network and the British Thyroid Association (110-112). Because of a lack of efficacy, ${ }^{131}$ I use (for imaging and therapy) is not recommended for patients with anaplastic $(113,114)$ or medullary thyroid carcinomas (MTCs) $(115,116)$, although its use should be considered similarly to DTC in those rare cases of MTC in which the tumor is admixed with DTC (116-118).

After total thyroidectomy and ${ }^{131}$ I therapy, patients with DTC commonly show an excellent response to treatment and are considered free of disease (remission) when their TSH-stimulated serum $\mathrm{Tg}$ level is $<1 \mathrm{ng} / \mathrm{mL}$ in the absence of anti-TgAbs and when there is no structural or functional evidence of disease (25). Patients without structural evidence of disease, but with an abnormal serum $\mathrm{Tg}$ or rising anti- $\mathrm{TgAb}$ level are considered to have a biochemically incomplete response (25). Similar considerations are applied to patients treated with total thyroidectomy without RAI and to those treated with a lobectomy alone, using different serum Tg cutoff values (119). Patients with rising Tg or anti-TgAb levels and those with structural evidence of disease are considered for additional investigations and therapies (25). Those with abnormal serum $\mathrm{Tg}$ or rising anti- $\mathrm{TgAb}$ levels may have no evidence of
IA thyroid tissue on whole-body radioiodine imaging despite appropriate preparation for imaging (e.g., avoidance of recent CT contrast) (120).

Despite negative results of a diagnostic RAI whole-body scan, RAI therapy may be considered, especially when the serum $\mathrm{Tg}$ or anti- $\mathrm{TgAb}$ level is rising or when the serum $\mathrm{Tg}$ value is markedly elevated, and anatomic imaging of the neck and chest (or ${ }^{18} \mathrm{~F}-\mathrm{FDG}$ PET/CT imaging) has failed to reveal a tumor source amenable to directed therapy (such as surgery) $(25,120) .{ }^{18} \mathrm{~F}-\mathrm{FDG}$-avid metastases are less likely to benefit from ${ }^{131}$ I therapy $(5,121,122)$. If the posttherapy ${ }^{131}$ I scan has negative results, the patient is less likely to have radioiodine-responsive disease and additional ${ }^{131} \mathrm{I}$ therapy may not be indicated $(25,76)$. The controversies and the many factors that affect the classification of radioiodine-refractory DTC are beyond the scope of this document but have been discussed elsewhere (76).

Patients with a history of DTC who manifest a suspicious lesion in the absence of supporting biochemical evidence of active DTC should be considered for a tissue biopsy of the lesion, or functional imaging to confirm RAI avidity, before consideration of treatment with ${ }^{131} \mathrm{I}$. This is also true for patients with biochemical evidence of active DTC who manifest a suspicious lesion in a location or pattern that is atypical for DTC.

\section{Clinical Scenarios and AUC Scores}

Clinical scenarios for the use of nuclear medicine and final AUC scores in ${ }^{131}$ I therapy for DTC in patients who have had total or near-total thyroidectomy are presented in Table 5.

Scenario 1: Ablation of Remnant Tissue (Remnant Ablation) (Score 8-Appropriate). ${ }^{131}$ I remnant ablation of residual normal thyroid tissue may be appropriate after optimal tumor resection of the primary tumor with total thyroidectomy and local-regional disease resection (25). Current evidence suggests no or limited benefit for patients with low-risk thyroid cancer and greater benefit for higher risk thyroid cancer $(24,25)$. (Refer to Appendix B for a more extensive discussion of risk terminology.) Pretherapy diagnostic imaging is appropriate and helpful to confirm the presence of iodine-avid disease, especially in cases with increased risk of residual disease, but it may not always be practical or necessary in selected scenarios.

Scenario 2: Adjuvant ${ }^{131}$ I Treatment (Score 8 - Appropriate). ${ }^{131}$ I treatment of suspected residual cancer is appropriate after optimal tumor resection of the primary tumor with total thyroidectomy and local-regional disease resection in patients at increased risk of cancer recurrence (25). Pretherapy diagnostic imaging is appropriate and helpful to confirm the presence of iodine-avid disease, especially in cases with increased risk of residual disease, but it may not always be practical or necessary in selected scenarios.

Scenario 3: Treatment of Regional and Distant Metastatic Disease (Score 9 -Appropriate). ${ }^{131}$ I treatment of residual cancer is appropriate after optimal tumor resection of the primary tumor with total thyroidectomy and local-regional disease resection. Pretherapy diagnostic imaging is appropriate and helpful to confirm the presence of iodine-avid disease, especially in cases with increased risk of residual disease, but it may not always be practical or necessary in selected scenarios.

Scenario 4: Treatment of Patients with Thyroid Cancer Who Have Had No Prior Thyroidectomy (Score 3 - Rarely Appropriate). Thyroidectomy is the most effective treatment for thyroid cancer in the thyroid gland. Radioiodine will preferentially 
TABLE 5

Clinical Scenarios for ${ }^{131}$ I Therapy in Thyroid Cancer

\begin{tabular}{|c|c|c|c|}
\hline Scenario no. & Description & Appropriateness & Score \\
\hline 1 & Ablation of remnant tissue & Appropriate & 8 \\
\hline 2 & Adjuvant ${ }^{131}$ I treatment & Appropriate & 8 \\
\hline 3 & Treatment of regional and distant metastatic disease & Appropriate & 9 \\
\hline 4 & $\begin{array}{l}\text { Treatment of patients with thyroid cancer who have had no prior } \\
\text { thyroidectomy }\end{array}$ & Rarely appropriate & 3 \\
\hline 5 & $\begin{array}{l}\text { Thyroid cancer in patient with hemithyroidectomy and remaining } \\
\text { residual functioning of thyroid lobe }\end{array}$ & May be appropriate & 4 \\
\hline 6 & $\begin{array}{l}\text { Abnormal } \mathrm{Tg} \text { (or elevated anti-TgAb) level - no evidence of IA thyroid } \\
\text { tissue on whole-body imaging with radioiodine }\end{array}$ & May be appropriate & 5 \\
\hline 7 & $\begin{array}{l}\text { Abnormal } \mathrm{Tg} \text { (or elevated anti-TgAb) level in patients with no prior } \\
\text { response to } 131 \mid \text { therapy }\end{array}$ & May be appropriate & 4 \\
\hline 8 & Patient with history of DTC, uncharacterized new suspicious lesion & Rarely appropriate & 2 \\
\hline 9 & Anaplastic thyroid carcinoma & Rarely appropriate & 1 \\
\hline 10 & MTC & Rarely appropriate & 1 \\
\hline 11 & ${ }^{18} \mathrm{~F}-\mathrm{FDG}$ PET/CT shows ${ }^{18} \mathrm{~F}-\mathrm{FDG}$-avid lesion & May be appropriate & 5 \\
\hline 12 & $\begin{array}{l}\text { Residual IA thyroid tissue documented with radioiodine imaging after } \\
\text { total or near-total thyroidectomy in pregnant or lactating patients }\end{array}$ & Rarely appropriate & 1 \\
\hline 13 & Pregnant or lactating patients & Rarely appropriate & 1 \\
\hline
\end{tabular}

concentrate in normal thyroid tissue and minimally in DTC if there has not been a thyroidectomy. In poor surgical candidates, a stepwise ablation of the normal thyroid tissue followed by adjuvant therapy of the thyroid cancer is possible but less effective than surgical excision.

Scenario 5: Treatment of Thyroid Cancer in Patients with Hemithyroidectomy and Remaining Residual Functioning of the Thyroid Lobe (Score 4 - May Be Appropriate). In patients with hemithyroidectomy, surgical completion of thyroidectomy is advised before radioiodine therapy. As with patients who have not had prior thyroidectomy, radioiodine will preferentially concentrate in normal thyroid tissue and minimally in DTC if there has only been a hemithyroidectomy. In poor surgical candidates, a stepwise ablation of the normal thyroid tissue followed by adjuvant therapy of the thyroid cancer is possible but less effective than surgical excision.

Scenario 6: ${ }^{131} I$ Therapy for an Abnormal Tg (or elevated anti$T g A b)$ Level - No Evidence of IA Thyroid Tissue on Whole-Body Imaging with Radioiodine (Score 5 - May Be Appropriate). The expert panel believes that therapy of such patients may be appropriate, but with significant caution. There is concern that such patients harbor residual thyroid cancer that may not concentrate RAI adequately to be visualized on diagnostic imaging but may retain enough activity from ${ }^{131}$ I therapy to be effective. In these patients, there is particular concern that side effects may occur in nontarget tissues if a large treatment dose is given. It may be appropriate to actively surveil patients with modestly elevated serum $\mathrm{Tg}$ levels in the absence of structurally evident disease. Empiric ${ }^{131} \mathrm{I}$ therapy may be appropriate for patients with more significantly elevated serum $\mathrm{Tg}$ levels, or when the serum $\mathrm{Tg}$ or anti-Tg levels are rising, and imaging has failed to identify structural disease that is more suitable for alternative treatments.

Scenario 7: ${ }^{131} I$ Therapy for an Abnormal $\mathrm{Tg}$ (or elevated antiTgAb) Level in Patients with No Prior Response to ${ }^{131}$ I Therapy
(Score 4-May Be Appropriate). The expert panel opinion is that additional RAI therapy may be appropriate in the setting of an abnormal serum $\mathrm{Tg}$ or anti- $\mathrm{TgAb}$ level when prior therapy demonstrated no response, especially when the biomarker is rising or the serum $\mathrm{Tg}$ level is markedly elevated. However, there is significant concern that the additional treatment will also be of no benefit. Anatomic imaging of the neck and chest (or ${ }^{18} \mathrm{~F}-\mathrm{FDG}$ PET/CT imaging) to identify disease that may be observed or treated with alternative strategies should be a priority. Evidence of RAI-avid disease on a pretherapy diagnostic scan indicates tissue that is potentially responsive to RAI treatment, whereas negative results on a diagnostic scan in this setting is particularly worrisome that further RAI therapy will not be effective.

Scenario 8: ${ }^{131}$ I Therapy for Patients with a History of DTC and an Uncharacterized New Suspicious Lesion (Score 2 - Rarely Appropriate). The expert panel felt that the discovery of a suspicious lesion requires evaluation and characterization as IA thyroid cancer before consideration of ${ }^{131} \mathrm{I}$ treatment. This is considered by the expert panel to be standard of practice.

Scenario 9: ${ }^{131}$ I Therapy for Patients with Anaplastic Thyroid Carcinoma (Score 1 - Rarely Appropriate). ${ }^{131}$ I therapy is not effective treatment for anaplastic thyroid cancer because the tissue typically lacks the sodium iodide symporter needed to concentrate radioiodine. This is considered by the expert panel to be standard of practice.

Scenario 10: ${ }^{131}$ I Therapy for Patients with MTC (Score 1-Rarely Appropriate). RAI is not effective treatment for MTC. In rare cases, a total thyroidectomy sample may show mixed papillary and MTC within the same gland (123). In such cases, ${ }^{131}$ I therapy may be of benefit for treating the IA tissue.

Scenario 11: ${ }^{18}$ F-FDG PET/CT Shows an FDG-Avid Lesion (Score 5 - May Be Appropriate). FDG-avid lesions are suspicious for thyroid cancer and require further evaluation with radioiodine imaging before treatment with radioiodine. For patients with 
radioiodine-refractory disease, ${ }^{18} \mathrm{~F}-\mathrm{FDG}$ PET/CT imaging may lead to a change of management in $35 \%$ of cases (124).

Scenario 12: Residual IA Thyroid Tissue Documented with Radioiodine Imaging After Total or Near-Total Thyroidectomy in Pregnant or Lactating Patients (Score 1 - Rarely Appropriate). Pregnancy is a contraindication to radioiodine therapy. The radiation dose to the embryo/fetus can cause miscarriage, birth defects, cretinism, and an increase in childhood malignancies. RAI therapy while lactating is also contraindicated. Radioactive iodide is concentrated in the milk and can be delivered to the infant through ingestion of the milk, leading to irradiation of the infant's thyroid. To mitigate the radiation dose to the female breast and infant, breastfeeding should be stopped at least 4 (preferably 6) wk before administration of radioiodine and should not be restarted after administration of RAI (82). Lactation can be safely done with future pregnancies.

Scenario 13: Pregnant or Lactating Patients (Score 1 - Rarely Appropriate). Pregnancy is a contraindication to radioiodine therapy. The radiation dose to the embryo/fetus can cause miscarriage, birth defects, cretinism, and an increase in childhood malignancies. RAI therapy while lactating is also contraindicated. Radioactive iodide is concentrated in the milk and can be delivered to the infant through ingestion of the milk, leading to irradiation of the infant's thyroid. To mitigate the radiation dose to the female breast and infant, breastfeeding should be stopped at least 4 (preferably 6) wk before administration of radioiodine and should not be restarted after administration of RAI (82). Lactation can be safely done with future pregnancies.

\section{Summary of Recommendations}

${ }^{131}$ I therapy after total or near-total thyroidectomy for DTC is recognized as appropriate use for remnant tissue ablation, adjuvant treatment, and treatment of IA metastatic disease. Current evidence suggests no or limited benefit for patients with low-risk thyroid cancer and greater benefit for patients with higher risk thyroid cancer. Caution should be exercised when considering ${ }^{131}$ I therapy in the setting of a residual intact thyroid lobe (or lobes), in patients with biochemical evidence suggesting residual thyroid cancer when no IA thyroid tissue is present, when prior ${ }^{131}$ I therapy did not demonstrate a favorable response, or to treat ${ }^{18}$ F-FDG-avid thyroid cancer. Rarely, if ever, should ${ }^{131}$ I therapy be considered when the thyroid has not been surgically removed, when the patient is pregnant or lactating, to treat anaplastic thyroid carcinoma or MTC, or when a suspicious lesion(s) has not been adequately established as thyroid cancer.

\section{MTC-PERTECHNETATE IMAGING IN DTC}

\section{Introduction}

${ }^{99 \mathrm{~m}} \mathrm{Tc}$-pertechnetate is frequently used for thyroid scintigraphy in benign conditions and characteristically depicts a focus of DTC as a photopenic lesion. Under the stimulation of TSH, ${ }^{99 \mathrm{~m}} \mathrm{Tc}-$ pertechnetate can demonstrate posthyroidectomy benign remnant tissue and, in some cases, coexistent DTC tissue before RAI therapy. It can also show metastatic DTC on subsequent diagnostic imaging and may provide some insight into the ability of DTC to concentrate iodine (125).

\section{Background}

${ }^{99 m}$ Tc-pertechnetate is trapped by the sodium iodide symporter located on the surface of thyroid epithelial cells, as is iodide. However, unlike iodide, it cannot be organified within the thyrocyte. This explains the much longer residence of the iodide bound to organic molecules in benign and certain types of malignant thyroid tissues compared with ${ }^{99 \mathrm{~m}} \mathrm{Tc}$-pertechnetate, which can be easily displaced from the binding sites on the cellular surface. The longer intracellular residence of radioactive iodides in the thyrocytes allows for clearance of radioiodine from the more loosely bound background tissues. This clearance from background increases the target-to-background ratio in delayed imaging of radioiodine. In comparison, the more loosely bound ${ }^{99 \mathrm{~m}} \mathrm{Tc}$-pertechnetate must be imaged within an hour of tracer administration before activity is cleared from the target site. Despite this inherent drawback of ${ }^{99} \mathrm{~m}$ Tc-pertechnetate, it is considered an alternative to both ${ }^{123} \mathrm{I}$ and ${ }^{131}$ I for its 2 advantages: first, it does not cause stunning of thyrocytes (which may decrease subsequent uptake of radioiodine) and second, it is less expensive than radioiodine and more readily available at most facilities.

\section{Clinical Scenarios and AUC Scores}

Clinical scenarios for the use of nuclear medicine and final AUC scores in ${ }^{99} \mathrm{~m}$ Tc-pertechnetate imaging in DTC are presented in Table 6.

Scenario 1: Imaging of Suspected Thyroid Remnant After Total or NEAR-total Thyroidectomy (Score 5 - May Be Appropriate). In one recent investigation that compared ${ }^{99 \mathrm{~m}} \mathrm{Tc}$-pertechnetate neck and chest scintigraphy (TcNCS) with the reference standard imaging of a posttherapy ${ }^{131} \mathrm{I}$ scan performed 5-7 $\mathrm{d}$ after the first therapy after thyroidectomy in 174 patients with DTC (126), the 6 patients with no uptake on the ${ }^{131}$ I scan had no uptake on TcNCS. ${ }^{131}$ I patients $(75 \%)$ with at least 1 positive ${ }^{131} \mathrm{I}$ focus also had positive results on TcNCS. However, in 19 patients (11\%), uptake was equivocal on TcNCS at a site corresponding to clear ${ }^{131} \mathrm{I}$ activity. In an additional 18 patients (10\%), there was no uptake of TcNCS at the site of subsequent ${ }^{131}$ I activity. Therefore, perpatient analysis revealed a sensitivity of $78 \%$ and $90 \%$ for positive TcNCS results and a combination of positive and equivocally positive TcNCS results, respectively. The positive predictive value of TcNCS was $100 \%$. This was confirmed in a more recent study by using the same reference standard, showing $79 \%$ sensitivity and

TABLE 6

Clinical Scenarios for ${ }^{99 m}$ Tc-Pertechnetate Imaging in DTC

\begin{tabular}{|c|c|c|c|}
\hline Scenario no. & Description & Appropriateness & Score \\
\hline 1 & $\begin{array}{l}\text { Imaging of suspected thyroid remnant after total or near-total } \\
\text { thyroidectomy }\end{array}$ & May be appropriate & 5 \\
\hline 2 & $\begin{array}{l}\text { Imaging of suspected residual or recurrent DTC after total or near- } \\
\text { total thyroidectomy }\end{array}$ & May be appropriate & 5 \\
\hline 3 & Imaging of thyroid cancer before total or near-total thyroidectomy & Rarely appropriate & 1 \\
\hline 4 & Pregnant or lactating patients & Rarely appropriate & 1 \\
\hline
\end{tabular}


$100 \%$ positive predictive value on per-patient analysis (127). Therefore, TcNCS may be appropriate in situations in which RAI imaging is undesirable because of a high likelihood of stunning or a clinically based anticipation of a large thyroid remnant. One such scenario includes a patient who, after standard thyroid hormone withdrawal, fails to raise intrinsic TSH levels above 35 mIU/L. In such cases, imaging with RAI may be undesirable because of a higher likelihood of stunning.

Scenario 2: Imaging of Suspected Residual or Recurrent DTC After Total or Near-Total Thyroidectomy (Score 3 - Rarely Appropriate). The sensitivity of ${ }^{99 \mathrm{~m}}$ Tc-pertechnetate WBS (TcWBS) was generally low for detection of DTC in a consecutive cohort of patients. The most technically sophisticated study on the subject included 416 patients and used SPECT/CT for confirmation of planar findings (127). The sensitivity and specificity of TcWBS for lymph node metastases was $60 \%$ and $99 \%$, respectively, and for distant metastases was $37 \%$ and $99 \%$, respectively. In another study of 184 patients with DTC after thyroidectomy, ${ }^{99 \mathrm{~m}} \mathrm{Tc}$ pertechnetate neck and chest imaging combined with SPECT/CT had an overall concordance rate of $65.7 \%$ with a planar post- ${ }^{131} \mathrm{I}$ therapy whole-body ${ }^{131}$ I scan combined with SPECT/CT when metastases of all types (nodal, lung, bone) were included (125). In addition, the authors showed that patients with concordant lesions had a much greater reduction in $\mathrm{Tg}$ levels than did those who had IA lesions that were negative on TcWBS. This correlation makes sense as reasoned by the authors, who explained that greater uptake of therapeutic ${ }^{131}$ I would be expected in ${ }^{99 \mathrm{~m}} \mathrm{Tc}$-pertechnetate-avid lesions (125). These results were confirmed in an observational cohort of 56 patients (128). In this perpatient analysis, there was overall concordance of $96.4 \%$ between TcWBS with SPECT/CT of the neck and chest and findings on posttherapy scans. In per-site analysis for thyroid bed, lymph node, lung, and bone lesions, the percentage of concordance between the 2 modalities was $96.4 \%, 92.9 \%, 98.2 \%$, and $100 \%$, respectively.

Scenario 3: Imaging of Thyroid Cancer Before Total or NearTotal Thyroidectomy (Score 1 - Rarely Appropriate). Imaging of thyroid cancer with ${ }^{99 \mathrm{~m}} \mathrm{Tc}$-pertechnetate before total or near-total thyroidectomy is rarely appropriate. We have found no literature to support this scenario.

Scenario 4: Pregnant or Lactating Patients (Score 1 - Rarely Appropriate). Pregnancy and lactation are contraindications to the administration of ${ }^{99 \mathrm{~m}} \mathrm{Tc}$-pertechnetate. It would be trapped in the fetal thyroid and may cause some degree of hypothyroidism in the fetus if the concentration is high. The largest effect would likely be at a gestational age of approximately $3 \mathrm{mo}$. Administration of ${ }^{99 \mathrm{~m}} \mathrm{Tc}$-pertechnetate to a lactating patient is also contraindicated. Exposure of the neonate would be due to ${ }^{99 \mathrm{~m} T c-p e r t e c h n e t a t e ~ i n ~ t h e ~}$ milk, as well as direct exposure from the breast. However, if administration of ${ }^{99 \mathrm{~m}} \mathrm{Tc}$-pertechnetate to the mother is important, breastfeeding could be stopped for $3 \mathrm{~d}$. The milk expressed during that time could be placed in cold storage and given to the infant after decay of the radioisotope after approximately $3 \mathrm{~d}$ (129).

\section{Summary of Recommendations}

${ }^{99 m}$ Tc-pertechnetate imaging of a suspected thyroid remnant after total or near-total thyroidectomy may be appropriate if ${ }^{123} \mathrm{I}$ or ${ }^{131} \mathrm{I}$ are not available or otherwise contraindicated. Imaging of suspected residual or recurrent DTC after total or near-total thyroidectomy may be appropriate as well; however, ${ }^{123} \mathrm{I}$ or ${ }^{131} \mathrm{I}$ is preferred. Imaging of thyroid cancer before total or near-total thyroidectomy is rarely appropriate. Imaging with ${ }^{99 \mathrm{~m}} \mathrm{Tc}$-pertechnetate in the pregnant or lactating patient is rarely appropriate.

\section{F-FDG IMAGING IN DTC}

\section{Introduction}

${ }^{18}$ F-FDG PET/CT is widely used to guide clinical management of many neoplastic diseases, including primary staging, assessment of response to therapy, metabolic characterization of a tumor, and restaging. The use of ${ }^{18} \mathrm{~F}$-FDG PET/CT in a variety of malignancies has resulted in the discovery of thyroid incidental findings, some of which were subsequently diagnosed as DTC. DTC is a spectrum of phenotypically and histopathologically different diseases that are amenable to characterization from their expression of the sodium iodide symporter by using diagnostic RAI scintigraphy or their expression of metabolic activity by using ${ }^{18} \mathrm{~F}-\mathrm{FDG}$ PET/CT imaging. For patients with DTC, ${ }^{18} \mathrm{~F}$-FDG PET/CT is most commonly used with recurrent NIA DTC as determined by a rising Tg level and negative results of a radioiodine scan.

\section{Background}

Incidentally discovered focal ${ }^{18} \mathrm{~F}$-FDG PET/CT uptake in the thyroid conveys an increased risk of thyroid cancer but can also represent benign conditions such as an autonomously functioning adenoma. Incidentally discovered thyroid nodules should therefore be considered for ultrasound-guided fine-needle aspiration. Diffuse ${ }^{18} \mathrm{~F}$-FDG PET/CT uptake is usually associated with thyroiditis and requires no further investigation in patients with concordant laboratory and imaging findings $(130,131)$. Thyroid nodules with indeterminate cytologic findings have been studied with ${ }^{18} \mathrm{~F}$-FDG PET/CT, but the evidence is insufficient for routine clinical use (132). These lesions may benefit from further molecular testing of their cytologic specimen.

${ }^{18} \mathrm{~F}-\mathrm{FDG} \mathrm{PET} / \mathrm{CT}$ is a second-line imaging study in patients with DTC. It is performed most commonly in patients with negative results on a diagnostic RAI scan yet persistent biochemical evidence of DTC, typically an elevated or increasing $\mathrm{Tg}$ or $\mathrm{TgAb}$ level $(63,133)$. In cases in which the $\mathrm{Tg}$ value is unreliable because of the presence of $\operatorname{TgAb}$, elevated or increasing levels of the latter can be used as a proxy for disease presence or progression, justifying investigation with ${ }^{18} \mathrm{~F}-\mathrm{FDG} \mathrm{PET} / \mathrm{CT}$. Another frequent reason for ${ }^{18} \mathrm{~F}-\mathrm{FDG}$ PET/CT is evaluation of the extent of DTC (133).

In addition, ${ }^{18} \mathrm{~F}-\mathrm{FDG} \mathrm{PET} / \mathrm{CT}$ is useful in staging and surveillance of cases of less differentiated (medullary, undifferentiated, and anaplastic) thyroid cancers. In anaplastic thyroid cancer, ${ }^{18} \mathrm{~F}$ FDG PET/CT is considered before initiation of therapy and to follow up on response to therapy every 3-6 mo.

The initial report on dual $\left({ }^{18} \mathrm{~F}-\mathrm{FDG}\right.$ and RAI) characterization of DTC revealed that while most of the cases $(61 \%)$ showed an inverse relationship (when either tracer showed increased uptake, the other would be decreased), there were overall 5 distinct patterns (134). However, defining the specific subtype of thyroid cancer by using this dual-isotope characterization system has not been sufficiently validated.

ATA recommendations state the following: " ${ }^{18}$ FDG PET imaging is not routinely recommended for the evaluation of thyroid nodules with indeterminate cytology.... Routine preoperative ${ }^{18}$ FDG PET scanning is not recommended.... ${ }^{18}$ FDG PET scanning should be considered in high-risk DTC patients with an elevated serum Tg level (generally $>10 \mathrm{ng} / \mathrm{mL}$ ) with negative findings on RAI imaging. ${ }^{18}$ FDG PET scanning may also be considered as (i) a part of initial staging in poorly differentiated thyroid cancers and invasive Hürthle cell carcinomas, especially those with other evidence of disease on imaging or because of elevated serum $\mathrm{Tg}$ levels, (ii) a prognostic tool in patients with metastatic disease to identify lesions 
and patients at highest risk for rapid disease progression and disease-specific mortality, and (iii) an evaluation of post treatment response after systemic or local therapy of metastatic or locally invasive disease" (25).

\section{Clinical Scenarios and AUC Scores}

Clinical scenarios for the use of nuclear medicine and final AUC scores for ${ }^{18} \mathrm{~F}-\mathrm{FDG}$ imaging in DTC are presented in Table 2.

Scenario 1: Evaluation for Thyroid Cancer with a Detectable Tg (or Elevated Anti-TgAb) Level and Negative Findings on Radioiodine Scan (Score 8 - Appropriate). When a patient with a history of thyroid cancer has evidence of active cancer by elevation of a tumor marker (63) or its surrogate (anti- $\mathrm{TgAb}$ ), but has negative results on an RAI scan, a whole-body ${ }^{18} \mathrm{~F}$-FDG PET/CT scan may be helpful to determine tumor burden and location.

Scenario 2: Suspected ${ }^{18}$ F-FDG-Avid Thyroid Cancer in Patients After Total or Near-Total Thyroidectomy (Score 8-Appropriate). If histopathology after a total or near-total thyroidectomy shows a more aggressive tumor type, a postoperative whole-body ${ }^{18} \mathrm{~F}$-FDG PET/CT scan should be considered to establish the baseline status of residual locoregional or distant metastatic disease.

Scenario 3: Established Thyroid Cancer in Patients Before Thyroidectomy (Score 4 - May Be Appropriate). Rarely is prethyroidectomy ${ }^{18} \mathrm{~F}-\mathrm{FDG}$ PET/CT scanning indicated for DTC. ${ }^{18} \mathrm{~F}-\mathrm{FDG}$ is usually a second-line imaging study, most commonly done if residual DTC is suspected and RAI scans show no localization of disease. In DTC, RAI diagnostic staging is rarely done before thyroidectomy; therefore, ${ }^{18} \mathrm{~F}$-FDG imaging of thyroid cancer before thyroidectomy is not commonly done. A preoperative ${ }^{18} \mathrm{~F}-\mathrm{FDG}$ $\mathrm{PET} / \mathrm{CT}$ scan is more commonly indicated when thyroid cancer cytology or open biopsy indicates a poorly differentiated or anaplastic thyroid carcinoma. ${ }^{18} \mathrm{~F}-\mathrm{FDG}$ imaging may then be helpful in planning management.

Scenario 4: Established ${ }^{18} \mathrm{~F}-\mathrm{FDG}$-Avid Thyroid Cancer in Patients After Thyroidectomy (Score 8-Appropriate). After a patient has been established as ${ }^{18}$ F-FDG PET avid, the expert panel felt it is appropriate to use whole-body ${ }^{18} \mathrm{~F}$-FDG PET/CT imaging for evaluation of response to therapy and surveillance.

Scenario 5: Pregnant or Lactating Patients (Score 1 - Rarely Appropriate). Given the risks with fetal exposure to ionizing radiation, ${ }^{18} \mathrm{~F}-\mathrm{FDG} \mathrm{PET} / \mathrm{CT}$ for thyroid cancer diagnosis or surveillance would be rarely indicated for pregnant patients with thyroid cancer. Nursing mothers excrete little ${ }^{18}$ F-FDG into the breast milk; however, uptake of ${ }^{18} \mathrm{~F}-\mathrm{FDG}$ into lactating breasts is substantial and will subject the infant to increased radiation exposure during nursing. In addition, the concentration of tracer in the lactating breast increases radiation exposure to the breast tissue (135). If ${ }^{18} \mathrm{~F}$-FDG imaging is necessary during lactation, the breast milk may be expressed and given to the infant by bottle. Normal breastfeeding may be resumed the day after ${ }^{18} \mathrm{~F}-\mathrm{FDG}$ administration, after decay of the isotope.

\section{Summary of Recommendations}

${ }^{18} \mathrm{~F}$-FDG PET/CT is a useful imaging tool for the localization of thyroid cancer in patients with negative results of RAI scans when they are suspected to have residual neoplastic thyroid disease. Localization of a solitary metastasis with ${ }^{18} \mathrm{~F}-\mathrm{FDG}$ may allow curative surgery, and discovery of disseminated tumor metastases may assist in localizing tissue for biopsy. Treatment management can be affected by determination of tumor burden and by after response to therapy. Occasionally patients with aggressive histologic findings on initial surgery that portend a loss of iodine avidity may be imaged with ${ }^{18}$ F-FDG. A stronger case can be made for the use of ${ }^{18} \mathrm{~F}$-FDG to follow those patients who have previously demonstrated ${ }^{18} \mathrm{~F}$-FDG-avid disease. ${ }^{18} \mathrm{~F}$-FDG PET/CT should be avoided in pregnant and lactating patients. Rarely is ${ }^{18} \mathrm{~F}-$ FDG PET indicated in patients with a thyroid neoplasm before thyroidectomy.

\section{METHOXYISOBUTYLISONITRILE (MIBI) IMAGING IN DTC}

\section{Introduction}

99mTc-MIBI ( ${ }^{99 m}$ Tc-sestamibi), a positively charged lipophilic agent most commonly used to demonstrate blood flow in myocardial perfusion imaging, has also shown utility in imaging malignancy, including DTC $(136,137)$. Although ${ }^{18}$ F-FDG can demonstrate glucose utilization and iodine can demonstrate incorporation of iodine into thyrocytes, sestamibi can demonstrate blood flow by using yet another physiologic pathway to identify differentiated thyroid malignancy.

\section{Background}

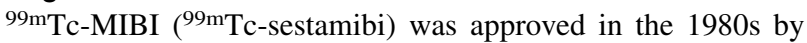
the FDA for myocardial perfusion imaging, and subsequently ${ }^{99 \mathrm{~m}} \mathrm{Tc}$-sestamibi was found to have utility in imaging neoplastic disease. It was approved by the FDA for imaging breast cancer, and many reports in the 1980s and 1990s demonstrated the utility of ${ }^{99} \mathrm{~m}$ Tc-sestamibi in patients with DTC, elevated $\mathrm{Tg}(63)$ or anti$\mathrm{TgAb}$ levels, and negative results of radioiodine scans ( $\mathrm{Tg}+/$ scan-). Although the widespread implementation of ${ }^{18} \mathrm{~F}$-FDG PET replaced the routine use of ${ }^{99 \mathrm{~m}} \mathrm{Tc}$-sestamibi imaging in these patients (128), the original publications and, most important, the different uptake mechanisms of ${ }^{99 \mathrm{~m}} \mathrm{Tc}-$-sestamibi and ${ }^{18} \mathrm{~F}-\mathrm{FDG}$, offer support for selected use of ${ }^{99 \mathrm{~m}} \mathrm{Tc}$-sestamibi in difficult patients with suspected residual thyroid neoplasm and no other imaging evidence of disease (e.g., negative RAI, ultrasound, ${ }^{18}$ F-FDG PET/CT, and CT scan results).

\section{Clinical Scenarios and AUC Scores}

Clinical scenarios for the use of nuclear medicine and final AUC scores in ${ }^{99 m} \mathrm{Tc}$-sestamibi imaging in DTC are presented in Table 7.

Scenario 1: Imaging of Suspected Thyroid Remnant After Total or Near-Total Thyroidectomy (Score 5 - May Be Appropriate). If one wishes to image thyroid remnant tissue after total or near-total thyroidectomy, the preferred radiopharmaceuticals are ${ }^{131} \mathrm{I},{ }^{123} \mathrm{I}$, or ${ }^{99 \mathrm{~m}} \mathrm{Tc}$-pertechnetate. ${ }^{99 \mathrm{~m}} \mathrm{Tc}$-sestamibi is not a preferred radiopharmaceutical but may be used if there are difficulties obtaining radioiodine or if there is a concern for lack of the NaI symporter.

Scenario 2: Evaluation for Thyroid Cancer with a Detectable Tg (or elevated anti-TgAb) Level and Negative Results of Radioiodine, Ultrasound, and ${ }^{18}$ F-FDG PET and Diagnostic CT Scans (Score 5 - May Be Appropriate). The selected use of ${ }^{99 \mathrm{~m}} \mathrm{Tc}$-sestamibi is reasonable in select patients with elevated or rapidly rising $\mathrm{Tg}$ or anti- $\mathrm{TgAb}$ levels and with negative findings on all other conventional imaging studies. However, currently there are no data to support a specific threshold for a blood level or doubling time of $\mathrm{Tg}$ or anti- $\mathrm{TgAb}$ to indicate when ${ }^{99 \mathrm{~m}} \mathrm{Tc}$-sestamibi is appropriate. The authors of this document felt that without literature support for use of ${ }^{99 \mathrm{~m}} \mathrm{Tc}$-sestamibi in specific clinical scenarios, the decision to use this agent must be made on an individual patient basis.

Scenario 3: Pregnant or Lactating Patients (Score 1 - Rarely Appropriate). ${ }^{99 \mathrm{~m}} \mathrm{Tc}$-sestamibi is not indicated for pregnant or lactating patients. 
TABLE 7

Clinical Scenarios for MIBI Imaging in DTC

\begin{tabular}{|c|c|c|c|}
\hline Scenario no. & Description & Appropriateness & Score \\
\hline 1 & $\begin{array}{l}\text { Imaging of suspected thyroid remnant after } \\
\text { total or near-total thyroidectomy }\end{array}$ & May be appropriate & 5 \\
\hline 2 & $\begin{array}{l}\text { Evaluation for thyroid cancer with detectable } \mathrm{Tg} \text { (or elevated anti-TgAb) } \\
\text { level and negative results of radioiodine, ultrasound, } \\
\text { and }{ }^{18} \mathrm{~F} \text {-FDG PET and diagnostic CT scans }\end{array}$ & May be appropriate & 5 \\
\hline 3 & Pregnant or lactating patients & Rarely appropriate & 1 \\
\hline
\end{tabular}

\section{Summary of Recommendations}

${ }^{99 m}$ Tc-sestamibi imaging was frequently performed in patients with DTC during the 1980s and 1990s but was replaced by other imaging modalities such as ${ }^{18}$ F-FDG PET. However, in select patients with DTC, significantly elevated or rising serum Tg levels, and negative findings on conventional imaging (e.g., ultrasound, radioiodine imaging, CT, ${ }^{18} \mathrm{~F}$-FDG PET scanning), ${ }^{99 \mathrm{~m}} \mathrm{Tc}$-sestamibi imaging may be helpful to locate the site of disease (138).

\section{G-DOTATATE/DOTATOC PET/CT IMAGING IN DTC}

\section{Introduction}

Even though DTCs are not classified as neuroendocrine tumors, a substantial percentage exhibit cellular expression of the somatostatin receptor (SSTR). In DTC, SSTR expression can be found independently of glucose transporter overexpression (i.e., ${ }^{18} \mathrm{~F}-\mathrm{FDG}$ PET/CT negative). Therefore, radiolabeled somatostatin analogs can be useful for diagnostic imaging and for assessing suitability for peptide receptor radiotherapy (PRRT) of advanced thyroid carcinomas.

\section{Background}

Middendorp et al. (139) evaluated 12 patients with recurrent RAI-avid and RAI-negative DTC, comparing the results of ${ }^{18} \mathrm{~F}-\mathrm{FDG}$ and ${ }^{68} \mathrm{Ga}$-DOTATOC PET/CT. For 104 tumor lesions, ${ }^{18}$ F-FDG PET/CT showed only a slightly higher detection rate than did ${ }^{68} \mathrm{Ga}$-DOTATOC PET/CT in radioiodine-positive patients (28 of 31 vs. 25 of 31, respectively), whereas significant differences were seen in the group with negative results of ${ }^{131}$ I WBS (70 of 73 vs. 26 of 73, respectively, $P<0.01$ ). Three of 104 lesions were visible only by using ${ }^{68} \mathrm{Ga}$-DOTATOC PET/CT. Because of the much higher lesion detection rates, the authors concluded that ${ }^{18} \mathrm{~F}-\mathrm{FDG}$ PET/CT should be preferred to ${ }^{68} \mathrm{Ga}$-DOTATOC PET in the workup of radioiodine-negative DTC relapse.

Similar results were recently obtained by Vrachimis et al. (140) in a series of 12 patients with RAI-negative DTC. Overall ${ }^{18} \mathrm{~F}-\mathrm{FDG}$ PET/CT performed better than ${ }^{68} \mathrm{Ga}$-DOTATATE PET/CT because of the superiority of both CT and ${ }^{18} \mathrm{~F}$-FDG PET over ${ }^{68} \mathrm{Ga}$-DOTATATE $\mathrm{PET} / \mathrm{CT}$ in the detection of lung metastases. However, in the evaluation of extrapulmonary lesions, ${ }^{68} \mathrm{Ga}$-DOTATATE PET/CT was more sensitive but less specific than ${ }^{18} \mathrm{~F}-\mathrm{FDG}$ PET/CT. The authors concluded that ${ }^{68} \mathrm{Ga}$-DOTATATE PET/CT could be used in RAI-negative DTC to identify patients who are eligible for PRRT (e.g., with ${ }^{177} \mathrm{Lu}-$ DOTATATE), as an add-on to ${ }^{18} \mathrm{~F}-\mathrm{FDG}$ PET/CT to complete staging if ${ }^{18} \mathrm{~F}$-FDG PET/CT results are negative, or to identify additional foci that could alter the therapeutic approach.

Binse et al. (141) performed a ${ }^{68} \mathrm{Ga}$-DOTATOC PET/CT scan in 15 patients with RAI-negative DTC and negative ${ }^{18} \mathrm{~F}$-FDG PET results. ${ }^{68} \mathrm{Ga}$-DOTATOC PET/CT scan results were true-positive in 5 patients (10 tumor lesions) and false-positive in 1 patient. The rate of positive ${ }^{68} \mathrm{Ga}$-DOTATOC PET/CT results was significantly higher in poorly differentiated and oxyphilic carcinomas (4 of 4 patients) than in papillary ( 1 of 5 ) or follicular ( 0 of 6$)$ tumors. In 2 of 5 patients with true-positive findings on ${ }^{68} \mathrm{Ga}$-DOTATOC, CT alone but not ultrasound identified 2 of 10 tumor lesions, but in both patients, ${ }^{68} \mathrm{Ga}$-DOTATOC-PET/CT revealed further tumor lesions not detected by CT alone.

Overall, these preliminary results in small patient groups must be confirmed by more extensive studies. In the meantime, ${ }^{68} \mathrm{Ga}-$ DOTATOC PET/CT should be considered in the case of negative ${ }^{18}$ F-FDG PET results in patients with RAI-negative DTC who have elevated and rising Tg levels. Imaging with ${ }^{68} \mathrm{Ga}$-DOTATOC appears to be especially promising in poorly differentiated and oxyphilic subtypes of DTC (141).

\section{Clinical Scenarios and AUC Scores}

Clinical scenarios for the use of nuclear medicine and final AUC scores in ${ }^{68} \mathrm{Ga}$-DOTATATE PET/CT imaging in DTC are presented in Table 8.

Scenario 1: Evaluation of SSTR Expression for RAI-Refractory Thyroid Cancer (Score 4 - May Be Appropriate). Based on the available literature, the use of ${ }^{68} \mathrm{Ga}$-DOTATATE PET/CT should be considered in selected patients for whom there is a need to identify the source of elevated or rising $\mathrm{Tg}$ or anti-TgAb levels when all other conventional imaging study results are negative. However, currently no data support a specific threshold for a blood level or doubling time of $\mathrm{Tg}$ or anti-TgAb levels to indicate when ${ }^{68} \mathrm{Ga}$-DOTATATE PET/CT is appropriate to use. This judgment must be made on an individual patient basis.

TABLE 8

Clinical Scenarios for ${ }^{68} \mathrm{Ga}$-DOTATATE PET/CT Imaging in DTC

\begin{tabular}{lll}
\hline Scenario no. & \multicolumn{1}{c}{ Description } & Appropriateness \\
\hline 1 & Evaluation of SSTR expression for RAl-refractory thyroid cancer & May be appropriate \\
2 & Pregnant or lactating patients & Rarely appropriate \\
\hline
\end{tabular}


Scenario 2: Pregnant or Lactating Patients (Score 1 - Rarely Appropriate). ${ }^{68} \mathrm{Ga}$-DOTATATE PET/CT imaging is not indicated for pregnant or lactating patients.

\section{Summary of Recommendations}

The expert panel felt that although there is sparse support in the literature, ${ }^{68} \mathrm{Ga}$-DOTATATE PET/CT may be appropriate in selected thyroid cancer patients suspected of relapse (i.e., elevated/ increasing $\mathrm{Tg}$ or $\mathrm{TgAb}$ levels) when all other conventional imaging study results are negative. ${ }^{68} \mathrm{Ga}$-DOTATATE PET/CT should be avoided in pregnant and lactating patients. ${ }^{68} \mathrm{Ga}$-DOTATATE PET/CT is not indicated for patients with a thyroid neoplasm before thyroidectomy.

\section{LU-DOTATATE TREATMENT IN DTC}

\section{Introduction}

Approximately $20 \%-30 \%$ of patients with metastatic DTC and most patients with Hürthle cell thyroid cancer are refractory to RAI and overall survival for these patients ranges between 2.5 and 4.5 y $(5,6,142)$. PRRT with radiolabeled somatostatin analogs has shown promise for treatment of RAI-refractory metastatic DTC with a demonstrated objective response rate of $27 \%-60 \%$ tumor reduction, as determined by radiologic measurements following the Response Evaluation Criteria In Solid Tumors (RECIST) guideline $(144,145)$.

\section{Background}

Even though DTCs are not classified as neuroendocrine tumors, a significant percentage of patients with advanced RAI-refractory DTCs express SSTR and can be imaged with ${ }^{68}$ Ga-DOTATATE PET/CT or ${ }^{111}$ In-pentetreotide. Therefore, PRRT should be considered in properly defined RAI-refractory advanced thyroid carcinomas with proven SSTR expression via ${ }^{68} \mathrm{Ga}$-DOTATATE PET/ CT or ${ }^{111}$ In-pentetreotide (144).

\section{Clinical Scenarios and AUC Scores}

Clinical scenarios for the use of nuclear medicine and final AUC scores for ${ }^{177} \mathrm{Lu}$-DOTATATE treatment in DTC are presented in Table 9.

Scenario 1: ${ }^{177}$ Lu-DOTATATE Treatment for Documented SSTRExpressing RAI-Refractory Thyroid Cancer (Score 4 - May Be Appropriate). PRRT with radiolabeled somatostatin analogs has shown promise for the treatment of RAI-refractory metastatic DTC with a demonstrated objective response rate of $27 \%-60 \%$ tumor reduction, as determined by radiologic measurements following RECIST $(143,144)$.

Scenario 2: ${ }^{177} \mathrm{Lu}$-DOTATATE Treatment for Documented SSTRExpressing RAI-Refractory Thyroid Cancer in Pregnant or Lactating Patients (Score 1 - Rarely Appropriate). ${ }^{177}$ Lu-DOTATATE treatment in is not indicated in pregnant or lactating patients.

\section{Summary of Recommendations}

There is preliminary evidence that treatment with ${ }^{177} \mathrm{Lu}$ - somatostatin analogs may be helpful in patients with thyroid cancer with a neoplasm that has been demonstrated to be RAI-negative and SSRTpositive. While such therapy is currently available at only a few specialized centers, it may be considered on an individual basis in patients with RAI-refractory advanced DTC.

\section{BENEFITS AND HARMS OF IMPLEMENTING THE AUC GUIDANCE}

During the last 2 decades, the development of AUC (2), also known as appropriateness criteria, has been undertaken for many medical conditions and clinical scenarios with the goal of improving the quality, efficiency, and cost-effectiveness of health care. Section 218(b) of the Protecting Access to Medicare Act of 2014 amended Title XVIII of the Social Security Act to direct the CMS to establish a program to promote the use of AUC (2) for advanced diagnostic imaging services. AUC are defined as criteria that are evidence based (to the extent feasible) and that assist professionals who order and furnish applicable imaging services to make the most appropriate treatment decisions for a specific clinical condition. As part of US health care reform efforts (starting January 1, 2018), physicians are required to document that they are following AUC (2) for outpatient medical imaging orders by using CDS software documentation. The software must be certified by the CMS in order to receive full reimbursement for diagnostic imaging services for Medicare and Medicaid patients. This affects advanced outpatient imaging for CT, MRI, and nuclear imaging/ quantification. This lead by CMS will likely be followed by private insurance.

The theoretic benefits of AUC implementation include reduced waste in redundant and inappropriate medical imaging, which may reduce costs and radiation exposure to patients. Potential harms include delay of necessary imaging or denial of imaging that could have benefited a patient. Great care has been exercised by the SNMMI and its AUC panel on the evaluation and treatment of DTC to systematically comb the literature for evidence and guidelines/best practices in this domain. It is the goal of our group that the synthesis of available data will result in AUC that can be incorporated into artificial intelligence that will assist providers and clinicians with effective CDS for imaging of DTC.

\section{QUALIFYING STATEMENTS}

\section{Considerations for Pregnant or Lactating Patients ( ${ }^{131}$ I or ${ }^{123}$ )}

It is critical to determine the pregnancy or lactation status of female patients of child-bearing potential before administration of radioiodine. Radiation exposure to the fetal thyroid from ${ }^{131} \mathrm{I}-\mathrm{NaI}$ is very high (1), and administration of radioiodine to a pregnant patient is absolutely contraindicated. Radioiodine crosses the placenta, and ${ }^{131} \mathrm{I}-\mathrm{NaI}$ will destroy the fetal thyroid, which begins to form at a gestational age of approximately $10 \mathrm{wk} .{ }^{123} \mathrm{I}-\mathrm{NaI}$ has a much lower radiation dose, but even at an administered activity of 74-111 MBq (2-3 mCi) for a whole-body scan, there can be substantial damage to the fetal thyroid (131).

Use of radioiodine is also absolutely contraindicated in lactating patients, and complete cessation of breastfeeding is required. Radioiodine is excreted in breast milk, and so a breastfeeding infant would receive radiation exposure from close proximity to the breast, as well as radioiodine in the milk, which would ultimately expose the infant's thyroid. Breastfeeding cannot be resumed for that infant but breastfeeding a subsequent infant is considered safe.

\section{IMPLEMENTATION OF THE AUC GUIDANCE}

To develop broad-based multidisciplinary clinical guidance documents, SNMMI has been working with several other medical specialty societies. It is hoped that this collaboration will foster the acceptance and adoption of this guidance by other specialties. SNMMI has developed a multipronged approach to disseminate AUC for nuclear medicine in the evaluation and treatment of DTC to all relevant stakeholders, including referring physicians, nuclear medicine physicians, and patients. The dissemination and implementation 


\begin{tabular}{ccc}
\hline Scenario no. & Description & Appropriateness \\
\hline 1 & 177 Lu-DOTATATE treatment for documented SSTR-expressing & May be appropriate \\
& RAI-refractory thyroid cancer & \\
2 & 177 Lu-DOTATATE treatment for documented SSTR-expressing & Rarely appropriate \\
& RAI-refractory thyroid cancer in pregnant or lactating patients & \\
\hline
\end{tabular}

tactics will include a mix of outreach and educational activities targeted to each of these audiences. SNMMI will create case studies for its members, as well as for referring physicians, and make them available via online modules and webinars. These cases will cover the appropriate clinical scenarios for the use of DTC studies. Related resources such as the systematic review supporting the development of these AUC, a list of upcoming education events on the AUC, factsheets, and other didactic materials will be made available on the SNMMI Web site. Live sessions will be held at the SNMMI annual and midwinter meetings, as well as at other relevant professional society meetings of referring physicians to highlight the importance and application of these AUC. SNMMI also aims to create a mobile application for these AUC for both Apple and Android platforms.

\section{ACKNOWLEDGMENTS}

The workgroup acknowledges staff support from the Pacific Northwest Evidence-Based Practice Center of Oregon Health and Science University (Roger Chou, MD, FACP - Principle Investigator; Rebecca Jungbauer, DrPH - Research Associate and Project Manager; Ian Blazina, MPH - Research Associate; Miranda Pappas, MA - Research Associate; Sara Grusing, BA - Research Assistant; Tracy Dana, MLS - Research Librarian; Elaine Graham, MLS EPC Operations Manager provided project oversight).

\section{APPENDIX A: WORKGROUP MEMBERS AND EXTERNAL REVIEWERS}

\section{Workgroup}

The members of the workgroup are Kevin J. Donohoe, MD (Chair), Beth Israel Deaconess Medical Center, Boston, MA (SNMMI); Jennifer Aloff, MD, FAAFP, Midland Family Physicians, PC, Midland, MI (AAFP); Anca M. Avram, MD, FACNM, University of Michigan Medical Center, Ann Arbor, MI (ACNM, SNMMI); KG Bennett, MD, Elmhurst Memorial Hospital, Downers Grove, IL (ACNM, SNMMI); Luca Giovanella, MD, PhD, IOSI Oncology Institute of Southern Switzerland, Bellinzona, Switzerland (EANM); Bennett S. Greenspan, MD, FACNM, FACR, FSNMMI North Augusta, SC (SNMMI, ACNM); Seza Gulec, MD, Aventura Hospital Medical Center, Aventura, FL (SNMMI); Aamna Hassan, MD, Shaukat Khanum Memorial Cancer Hospital and Research Center, Lahore, Pakistan; Richard T. Kloos, MD, Veracyte, Inc., South San Francisco, CA (ATA); Carmen C. Solórzano, MD, FACS, Vanderbilt University, Nashville, TN (AAES); Brendan C. Stack, Jr., MD, FACS, FACE, University of Arkansas for Medical Sciences, Little Rock, AR (AHNS); Mark Tulchinsky, MD, FACNM, CCD, Milton S. Hershey Medical Center, Hershey, PA (SNMMI); Robert M. Tuttle, MD, Memorial Sloan Kettering Center, Brewster, NY (AACE); Douglas Van Nostrand, MD, FACP, FACNM, MedStar Washington Hospital Center, Washington, DC (ACNM, ATA, AACE,
Endocrine Society, SNMMI); and Jason A. Wexler, MD, MedStar Washington Hospital Center, Washington, DC (Endocrine Society).

\section{External Reviewers}

The external (peer) reviewers are Alfredo Campenni, MD, University of Messina, Messina, Italy; Erica J. Cohen, DO, MPH, CCD, Edward Hines Jr. Veterans Administration Hospital, Hines, IL; James V. Hennessey, MD, Beth Israel Deaconess Medical Center, Boston, MA; Elif Hindie, MD, PhD, Bordeaux University Hospital, Bordeaux, France; Steven M. Larson, MD, FACNM, FACR, Memorial Sloan Kettering Cancer Center, New York, NY; Darlene Metter, MD, FACR, UT Health San Antonio, San Antonio, TX; Mona Natwa, MD, Ohio State University, Wexner Medical Center, Columbus, OH; William G. Spies, MD, Northwestern Memorial Hospital, Chicago, IL.

\section{SNMMI}

The supporting staff from SNMMI are Sukhjeet Ahuja, MD, MPH, Director, Health Policy \& Quality Department; Teresa Ellmer, MIS, CNMT, Senior Program Manager, Health Policy \& Quality Department; Julie Kauffman, Program Manager, Health Policy \& Quality Department.

\section{APPENDIX B: DEFINITIONS OF TERMS AND ACRONYMS}

AACE: American Association of Clinical Endocrinologists

AAES: American Association of Endocrine Surgeons

AAFP: American Academy of Family Physicians

ACNM: American College of Nuclear Medicine

AHNS: American Head and Neck Society

AMSTAR: A MeaSurement Tool to Assess systematic Reviews

ATA: American Thyroid Association

AUC: appropriate use criteria

CDS: clinical decision support

CMS: Centers for Medicare and Medicaid Services

COI: conflict of interest

CT: computed tomography

Dosage: an amount of administered radioactivity or medication

Dose: an amount of radiation exposure

DOTATATE/DOTATOC: compounds that can be chelated to radioisotopes and used to image tissues with a high concentration of somatostatin receptors

DTC: differentiated thyroid cancer

EANM: European Association of Nuclear Medicine 
FDA: Food and Drug Administration

${ }^{18}$ F-FDG: ${ }^{18}$ F-fluorodeoxyglucose

GRADE: Grading of Recommendations Assessment, Development and Evaluation

Gy: gray

${ }^{131}$ I adjuvant treatment: “. . . ${ }^{131}$ I administered in an effort to destroy subclinical tumor deposits that may or may not be present after surgical resection of all known primary tumor tissue and metastatic foci. The goals of adjuvant treatment are to improve disease specific survival, decrease recurrence rates, as well as to improve progression free survival. It is important to remember that since adjuvant treatment is given for a risk, rather than for known disease, it is accepted that some patients who receive adjuvant treatment might already have been treated sufficiently by their primary surgery. Therefore, selection for adjuvant treatment involves both an assessment of risk of differentiated thyroid cancer (DTC) recurrence/persistence and risk of dying of DTC as well as the prediction of the likelihood that ${ }^{131}$ I treatment may have a meaningful impact on an individual patient's course of disease" (145). Reproduced with permission from MaryAnn Liebert, Inc.

${ }^{131}$ I remnant ablation: "Remnant ablation refers to the use of ${ }^{131}$ I to destroy post-operatively residual, presumably benign thyroid tissue to facilitate initial staging and follow-up studies [such as serum thyroglobulin (63) and radioiodine imaging]" (145). Reproduced with permission from MaryAnn Liebert, Inc.

${ }^{131}$ I therapy: refers to ${ }^{131} \mathrm{I}$ remnant ablation, ${ }^{131} \mathrm{I}$ adjuvant treatment, or ${ }^{131} \mathrm{I}$ treatment of known disease (145)

${ }^{131}$ I treatment of locoregional and/or distant metastases: "Treatment of known biochemical or structural disease refers to the goal of destroying persistent or recurrent DTC foci with ${ }^{131} \mathrm{I}$ in order to improve progression free, disease specific and overall survival. It can be given either with curative or palliative intent" (145). Reproduced with permission from MaryAnn Liebert, Inc.

IA: iodine avid

MBq: megabecquerel

$\mathrm{mCi}$ : millicurie

MIBI: methoxyisobutylnitrile

MRI: magnetic resonance imaging

MTA: maximum tolerable activity

MTC: medullary thyroid carcinoma

NaI: sodium iodide

NIA: noniodine avid

OHSU: Oregon Health and Science University

PET: positron emission tomography

PET/CT: an imaging machine that can acquire both PET and CT images in succession without moving the patient; alternatively, PET/CT may refer to the images obtained from a PET/CT scanner

PRRT: peptide receptor radionuclide therapy

RAI: radioactive iodine

RAIU: radioactive iodine uptake
RECIST: Response Evaluation Criteria in Solid Tumors - a method used to evaluate tumor response to therapy by using CT scanning

RFBT: remnant functioning benign thyroid

rhTSH: recombinant human thyroid-stimulating hormone

Risk: clinico-pathologic risk stratification predicting the risk of disease recurrence or persistence $(24,25)$

${ }^{99 \mathrm{~m}} \mathrm{Tc}$-pertechnetate $\left({ }^{99} \mathrm{~m} \mathrm{TcO}_{4}{ }^{-}\right)$: the water-soluble oxygenated anion of the element ${ }^{99 \mathrm{~m}} \mathrm{Tc}$

99mTc-sestamibi: the isotope ${ }^{99 m} \mathrm{Tc}$ complexed with 6 molecules of methoxyisobutylnitrile (MIBI)

SNMMI: Society of Nuclear Medicine and Molecular Imaging

SPECT: single-photon emission computed tomography

SSTR: somatostatin receptor

TcNCS: ${ }^{99 \mathrm{~m}} \mathrm{Tc}-$ pertechnetate neck and chest scintigraphy

TcWBS: ${ }^{99 \mathrm{~m} T c-p e r t e c h n e t a t e}$ whole-body scintigraphy

Tg: thyroglobulin

TgAb: thyroglobulin antibody

TSH: thyroid-stimulating hormone

WBBD: whole-body blood dosimetry

WBS: whole-body scintigraphy

\section{APPENDIX C: DISCLOSURES AND CONFLICTS OF INTEREST (COIS)}

SNMMI rigorously attempted to avoid any actual, perceived, or potential COIs that might have arisen as a result of an outside relationship or personal interest on the part of the workgroup members or external reviewers. Workgroup members were required to provide disclosure statements of all relationships that might be perceived as real or potential COIs. These statements were reviewed and discussed by the workgroup chair and SNMMI staff and were updated and reviewed by an objective third party at the beginning of every workgroup meeting or teleconference. The disclosures of the workgroup members can be found in Table 10. A COI was defined as a relationship with industry - including consulting, speaking, research, and nonresearch activities - that exceeds $\$ 5,000$ in funding over the previous or upcoming 12-mo period. In addition, if an external reviewer was either the principal investigator of a study or another key member of the study personnel, that person's participation in the review was considered likely to present a COI. All reviewers were asked about any potential COI. A COI was also considered likely if an external reviewer or workgroup member was either the principal investigator or a key member of a study directly related to the content of this AUC document. All external reviewers were asked about any potential COI.

\section{APPENDIX D: PUBLIC COMMENTARY}

The workgroup solicited information from all communities through the SNMMI website and through direct solicitation of SNMMI members. The comments and input helped to shape the development of these AUC on the use of nuclear medicine in the evaluation and treatment of DTC. 
TABLE 10

Relationships with Industry and Other Entities

\begin{tabular}{|c|c|}
\hline $\begin{array}{l}\text { Workgroup } \\
\text { member }\end{array}$ & $\begin{array}{l}\text { Reported } \\
\text { relationships }\end{array}$ \\
\hline Aloff, Jennifer & - None \\
\hline Avram, Anca & - None \\
\hline Bennet, KG & - None \\
\hline Donohoe, Kevin & - None \\
\hline \multirow[t]{4}{*}{ Giovanella, Luca } & $\begin{array}{l}\text { Roche Diagnostics, speaker } \\
\text { program and advisor }\end{array}$ \\
\hline & $\begin{array}{l}\text { - Genzyme-Sanofi, speaker } \\
\text { program and advisor }\end{array}$ \\
\hline & -IBSA SA, speaker program \\
\hline & - BRAHMS, speaker program \\
\hline $\begin{array}{c}\text { Greenspan, } \\
\text { Bennett }\end{array}$ & - None \\
\hline Gulec, Seza & - None \\
\hline Hassan, Aamna & - None \\
\hline Kloos, Richard & - Veracyte, Inc., employee \\
\hline $\begin{array}{l}\text { Solórzano, } \\
\text { Carmen }\end{array}$ & - None \\
\hline $\begin{array}{l}\text { Stack, Jr., } \\
\text { Brendan }\end{array}$ & - Shine, speaker, Natpara \\
\hline Tulchinsky, Mark & - None \\
\hline Tuttle, Robert & $\begin{array}{l}\text { - Esai, consultant, kinase inhibitor } \\
\text { - Veracyte, Inc., consultant, } \\
\text { molecular evaluation of thyroid } \\
\text { nodules }\end{array}$ \\
\hline $\begin{array}{l}\text { Van Nostrand, } \\
\text { Douglas }\end{array}$ & $\begin{array}{l}\text { - Genzyme-Sanofi, speaker } \\
\text { program and advisor }\end{array}$ \\
\hline & $\begin{array}{l}\text { - Jubilant DraxImage, speaker } \\
\text { program and advisor }\end{array}$ \\
\hline Wexler, Jason & - None \\
\hline
\end{tabular}

\section{REFERENCES}

1. Becker DV, Sawin CT. Radioiodine and thyroid disease: the beginning. Semin Nucl Med. 1996;26:155-164.

2. Parkash R, deKemp RA, Ruddy TD, et al. Potential utility of rubidium 82 PET quantification in patients with 3-vessel coronary artery disease. J Nucl Cardiol. 2004; 11:440-449.

3. Protecting Access to Medicare Act of 2014, Pub L No. 113-93, 128 Stat 1040 (2014).

4. Durante C, Montesano T, Attard M, et al. Long-term surveillance of papillary thyroid cancer patients who do not undergo postoperative radioiodine remnant ablation: is there a role for serum thyroglobulin measurement? J Clin Endocrinol Metab. 2012;97:2748-2753.

5. Robbins RJ, Wan Q, Grewal RK, et al. Real-time prognosis for metastatic thyroid carcinoma based on 2-[18F]fluoro-2-deoxy-D-glucose-positron emission tomography scanning. J Clin Endocrinol Metab. 2006;91:498-505.

6. Schlumberger M, Brose M, Elisei R, et al. Definition and management of radioactive iodine-refractory differentiated thyroid cancer. Lancet Diabetes Endocrinol. 2014;2:356-358.

7. Dohán O, De la Vieja A, Paroder V, et al. The sodium/iodide Symporter (NIS): characterization, regulation, and medical significance. Endocr Rev. 2003;24:48-77.

8. Machac J. Thyroid cancer in pediatrics. Endocrinol Metab Clin North Am. 2016;45:359-404
9. Blumhardt R, Wolin EA, Phillips WT, et al. Current controversies in the initial post-surgical radioactive iodine therapy for thyroid cancer: a narrative review. Endocr Relat Cancer. 2014;21:R473-R484.

10. Hendel RC, Patel MR, Allen JM, et al. Appropriate use of cardiovascular technology: 2013 ACCF appropriate use criteria methodology update: a report of the American College of Cardiology Foundation appropriate use criteria task force. J Am Coll Cardiol. 2013;61:1305-1317.

11. Fitch K, Bernstein SJ, Aguilar MD, Burnand B. The RAND/UCLA Appropriateness Method User's Manual. Santa Monica, CA: RAND; 2001.

12. Institute of Medicine. Clinical Practice Guidelines We Can Trust. Washington, DC: National Academies Press; 2011.

13. Pacific Northwest Evidence-Based Practice Center. Systematic Review: Nuclear Medicine in the Diagnosis and Treatment of Differentiated Thyroid Cancer. Portland, OR: Oregon Health and Science University; 2018.

14. Shea BJ, Bouter LM, Peterson J, et al. External validation of a measurement tool to assess systematic reviews (AMSTAR). PLoS One. 2007;2:e1350.

15. Whiting PF, Rutjes AW, Westwood ME, et al. QUADAS-2: a revised tool for the quality assessment of diagnostic accuracy studies. Ann Intern Med. 2011;155:529-536.

16. AQA Principles for Appropriateness Criteria. London, UK: Assessment and Qualifications Alliance; 2009.

17. Atkins D, Best D, Briss PA, et al. Grading quality of evidence and strength of recommendations. BMJ. 2004;328:1490.

18. Avram AM, Esfandiari NH, Wong KK. Preablation 131-I scans with SPECT/ CT contribute to thyroid cancer risk stratification and 131-I therapy planning. J Clin Endocrinol Metab. 2015;100:1895-1902.

19. Avram AM, Fig LM, Frey KA, Gross MD, Wong KK. Preablation 131-I scans with SPECT/CT in postoperative thyroid cancer patients: what is the impact on staging? J Clin Endocrinol Metab. 2013;98:1163-1171.

20. Avram AM, Rosculet N, Esfandiari NH, et al. Differentiated thyroid cancer outcomes after surgery and activity-adjusted ${ }^{131} \mathrm{I}$ theragnostics. Clin Nucl Med. 2019;44:11-20.

21. Chen MK, Yasrebi M, Samii J, Staib LH, Doddamane I, Cheng DW. The utility of I-123 pretherapy scan in I-131 radioiodine therapy for thyroid cancer. Thyroid. 2012;22:304-309.

22. Van Nostrand D, Aiken M, Atkins F, et al. The utility of radioiodine scans prior to iodine 131 ablation in patients with well-differentiated thyroid cancer. Thyroid. 2009; 19:849-855.

23. Wong KK, Sisson JC, Koral KF, Frey KA, Avram AM. Staging of differentiated thyroid carcinoma using diagnostic ${ }^{131}$ I SPECT/CT. AJR. 2010;195:730-736.

24. American Thyroid Association (ATA) Guidelines Taskforce on Thyroid Nodules, Differentiated Thyroid CancerCooper DS, et al. Revised American Thyroid Association management guidelines for patients with thyroid nodules and differentiated thyroid cancer. Thyroid. 2009;19:1167-1214.

25. Haugen BR, Alexander EK, Bible KC, et al. 2015 American Thyroid Association Management Guidelines for Adult Patients with Thyroid Nodules and Differentiated Thyroid Cancer: The American Thyroid Association Guidelines Task Force on Thyroid Nodules and Differentiated Thyroid Cancer. Thyroid. 2016;26:1-133.

26. Avram AM, Wong KK, Fig LM. SPECT/CT for Thyroid Cancer Imaging. Berlin: Springer; 2014.

27. Wong KK, Zarzhevsky N, Cahill JM, Frey KA, Avram AM. Incremental value of diagnostic ${ }^{131} \mathrm{I}$ SPECT/CT fusion imaging in the evaluation of differentiated thyroid carcinoma. AJR. 2008;191:1785-1794.

28. Wong KK, Zarzhevsky N, Cahill JM, Frey KA, Avram AM. Hybrid SPECT-CT and PET-CT imaging of differentiated thyroid carcinoma. Br J Radiol. 2009;82: 860-876.

29. Hung BT, Huang SH, Huang YE, Wang PW. Appropriate time for post-therapeutic I-131 whole body scan. Clin Nucl Med. 2009;34:339-342.

30. Lee JW, Lee SM, Koh GP, Lee DH. The comparison of ${ }^{131}$ I whole-body scans on the third and tenth day after ${ }^{131} \mathrm{I}$ therapy in patients with well-differentiated thyroid cancer: preliminary report. Ann Nucl Med. 2011;25:439-446.

31. Salvatori M, Perotti G, Villani MF, et al. Determining the appropriate time of execution of an I-131 post-therapy whole-body scan: comparison between early and late imaging. Nucl Med Commun. 2013;34:900-908.

32. Grewal RK, Tuttle RM, Fox J, et al. The effect of posttherapy ${ }^{131}$ I SPECT/CT on risk classification and management of patients with differentiated thyroid cancer. J Nucl Med. 2010;51:1361-1367.

33. Ruf J, Lehmkuhl L, Bertram H, et al. Impact of SPECT and integrated low-dose CT after radioiodine therapy on the management of patients with thyroid carcinoma. Nucl Med Commun. 2004;25:1177-1182.

34. Chen L, Luo Q, Shen Y, et al. Incremental value of ${ }^{131}$ I SPECT/CT in the management of patients with differentiated thyroid carcinoma. J Nucl Med. 2008;49:1952-1957. 
35. Gray KD, Bannani S, Caillard C, et al. High-dose radioactive iodine therapy is associated with decreased risk of recurrence in high-risk papillary thyroid cancer. Surgery. 2019;165:37-43.

36. Filesi M, Signore A, Ventroni G, Melacrinis FF, Ronga G. Role of initial iodine131 whole-body scan and serum thyroglobulin in differentiated thyroid carcinoma metastases. J Nucl Med. 1998;39:1542-1546.

37. Oh JR, Byun BH, Hong SP, et al. Comparison of ${ }^{131} \mathrm{I}$ whole-body imaging, ${ }^{131} \mathrm{I}$ SPECT/CT, and ${ }^{18} \mathrm{~F}$-FDG PET/CT in the detection of metastatic thyroid cancer. Eur J Nucl Med Mol Imaging. 2011;38:1459-1468.

38. Song H, Mosci C, Akatsu H, Basina M, Dosiou C, Iagaru A. Diagnostic ${ }^{123}$ I whole body scan prior to ablation of thyroid remnant in patients with papillary thyroid cancer: implications for clinical management. Clin Nucl Med. 2018;43:705-709.

39. Barwick T, Murray I, Megadmi H, et al. Single photon emission computed tomography (SPECT)/computed tomography using Iodine-123 in patients with differentiated thyroid cancer: additional value over whole body planar imaging and SPECT. Eur J Endocrinol. 2010;162:1131-1139.

40. Spanu A, Solinas ME, Chessa F, Sanna D, Nuvoli S, Madeddu G. ${ }^{131}$ I SPECT/CT in the follow-up of differentiated thyroid carcinoma: incremental value versus planar imaging. J Nucl Med. 2009;50:184-190.

41. Sarkar SD, Kalapparambath TP, Palestro CJ. Comparison of ${ }^{123} \mathrm{I}$ and ${ }^{131} \mathrm{I}$ for whole-body imaging in thyroid cancer. J Nucl Med. 2002;43:632-634.

42. Morris LF, Waxman AD, Braunstein GD. The nonimpact of thyroid stunning: remnant ablation rates in ${ }^{131} \mathrm{I}$-scanned and nonscanned individuals. J Clin Endocrinol Metab. 2001;86:3507-3511.

43. Rosário PW, Barroso AL, Rezende LL, et al. $5 \mathrm{mCi}$ pretreatment scanning does not cause stunning when the ablative dose is administered within 72 hours. Arq Bras Endocrinol Metabol. 2005;49:420-424.

44. Silberstein EB. Comparison of outcomes after ${ }^{123} \mathrm{I}$ versus ${ }^{131} \mathrm{I}$ pre-ablation imaging before radioiodine ablation in differentiated thyroid carcinoma. $J \mathrm{Nucl}$ Med. 2007;48:1043-1046.

45. McDougall IR. $74 \mathrm{MBq}$ radioiodine ${ }^{131} \mathrm{I}$ does not prevent uptake of therapeutic doses of ${ }^{131} \mathrm{I}$ (i.e. it does not cause stunning) in differentiated thyroid cancer. Nucl Med Commun. 1997;18:505-512.

46. Yin Y, Mao Q, Chen S, Li N, Li X, Li Y. A clinical trial of optimal time interval between ablation and diagnostic activity when a pretherapy RAI scanning is performed on patients with differentiated thyroid carcinoma. Medicine (Baltimore). 2015;94:e1308.

47. Jeevanram RK, Shah DH, Sharma SM, Ganatra RD. Influence of initial large dose on subsequent uptake of therapeutic radioiodine in thyroid cancer patients. Int J Rad Appl Instrum B. 1986;13:277-279.

48. Huić D, Medvedec M, Dodig D, et al. Radioiodine uptake in thyroid cancer patients after diagnostic application of low-dose ${ }^{131}$ I. Nucl Med Commun. 1996;17:839-842.

49. Yeung HW, Humm JL, Larson SM. Radioiodine uptake in thyroid remnants during therapy after tracer dosimetry. J Nucl Med. 2000;41:1082-1085.

50. Cholewinski SP, Yoo KS, Klieger PS. RE OM. Absence of thyroid stunning after diagnostic whole-body scanning with $185 \mathrm{MBq}{ }^{131}$ I. J Nucl Med. 2000;41: 1198-1202.

51. Karam M, Gianoukakis A, Feustel PJ, Cheema A, Postal ES, Cooper JA. Influence of diagnostic and therapeutic doses on thyroid remnant ablation rates. Nucl Med Commun. 2003;24:489-495.

52. Sisson JC, Avram AM, Lawson SA, Gauger PG, Doherty GM. The so-called stunning of thyroid tissue. J Nucl Med. 2006;47:1406-1412.

53. McDougall IR, Iagaru A. Thyroid stunning: fact or fiction? Semin Nucl Med. 2011;41:105-112.

54. Avram AM, Dewaraja YK. Thyroid cancer radiotheragnostics: the case for activity adjusted (131)I therapy. Clin Transl Imaging. 2018;6:335-346.

55. Banerjee M, Wiebel JL, Guo C, Gay B, Haymart MR. Use of imaging tests after primary treatment of thyroid cancer in the United States: population based retrospective cohort study evaluating death and recurrence. BMJ. 2016;354:i3839.

56. Khorjekar GR, Van Nostrand D, Garcia C, et al. Do negative ${ }^{124}$ I pretherapy positron emission tomography scans in patients with elevated serum thyroglobulin levels predict negative ${ }^{131}$ I posttherapy scans? Thyroid. 2014;24:1394-1399.

57. Freudenberg LS, Jentzen W, Petrich T, et al. Lesion dose in differentiated thyroid carcinoma metastases after rhTSH or thyroid hormone withdrawal: ${ }^{124}$ I PET/CT dosimetric comparisons. Eur J Nucl Med Mol Imaging. 2010;37: 2267-2276.

58. Jentzen W, Freudenberg L, Bockisch A. Quantitative imaging of ${ }^{124} \mathrm{I}$ with PET/ CT in pretherapy lesion dosimetry: effects impairing image quantification and their corrections. Q J Nucl Med Mol Imaging. 2011;55:21-43.

59. Jentzen W, Hoppenbrouwers J, van Leeuwen P, et al. Assessment of lesion response in the initial radioiodine treatment of differentiated thyroid cancer using ${ }^{124}$ I PET imaging. J Nucl Med. 2014;55:1759-1765.
60. Jentzen W, Verschure F, van Zon A, et al. ${ }^{124}$ I PET assessment of response of bone metastases to initial radioiodine treatment of differentiated thyroid cancer. J Nucl Med. 2016;57:1499-1504.

61. Avram AM. Radioiodine scintigraphy with SPECT/CT: an important diagnostic tool for thyroid cancer staging and risk stratification. J Nucl Med. 2012;53: 754-764.

62. Fatourechi V, Hay ID, Mullan BP, et al. Are posttherapy radioiodine scans informative and do they influence subsequent therapy of patients with differentiated thyroid cancer? Thyroid. 2000;10:573-577.

63. Notghi A, Hutchinson R, Kumar D, Tulley N, Harding LK. Use of geometric center and parametric images in scintigraphic colonic transit studies. Gastroenterology. 1994;107:1270-1277.

64. Hocevar M, Auersperg M, Stanovnik L. The dynamics of serum thyroglobulin elimination from the body after thyroid surgery. Eur J Surg Oncol. 1997;23: 208-210.

65. Spencer CA. Clinical review: clinical utility of thyroglobulin antibody (TgAb) measurements for patients with differentiated thyroid cancers (DTC). J Clin Endocrinol Metab. 2011;96:3615-3627.

66. Mazzaferri EL, Kloos RT. Clinical review 128: current approaches to primary therapy for papillary and follicular thyroid cancer. J Clin Endocrinol Metab. 2001;86:1447-1463.

67. Campennì A, Giovanella L, Pignata SA, et al. Undetectable or low $(<1 \mathrm{ng} / \mathrm{ml})$ postsurgical thyroglobulin values do not rule out metastases in early stage differentiated thyroid cancer patients. Oncotarget. 2018;9:17491-17500.

68. Giovanella L, Clark PM, Chiovato L, et al. Thyroglobulin measurement using highly sensitive assays in patients with differentiated thyroid cancer: a clinical position paper. Eur J Endocrinol. 2014;171:R33-R46.

69. Giovanella L, Treglia G, Sadeghi R, Trimboli P, Ceriani L, Verburg FA. Unstimulated highly sensitive thyroglobulin in follow-up of differentiated thyroid cancer patients: a meta-analysis. J Clin Endocrinol Metab. 2014;99:440-447.

70. Malandrino P, Tumino D, Russo M, Marescalco S, Fulco RA, Frasca F. Surveillance of patients with differentiated thyroid cancer and indeterminate response: a longitudinal study on basal thyroglobulin trend. J Endocrinol Invest. 2019;42:1223-1230.

71. de Keizer B, Koppeschaar HP, Zelissen PM, et al. Efficacy of high therapeutic doses of iodine-131 in patients with differentiated thyroid cancer and detectable serum thyroglobulin. Eur J Nucl Med. 2001;28:198-202.

72. Koh JM, Kim ES, Ryu JS, Hong SJ, Kim WB, Shong YK. Effects of therapeutic doses of ${ }^{131} \mathrm{I}$ in thyroid papillary carcinoma patients with elevated thyroglobulin level and negative ${ }^{131}$ I whole-body scan: comparative study. Clin Endocrinol (Oxf). 2003;58:421-427.

73. Wartofsky L. Management of the patients with negative radioiodine scan and elevated serum thyroglobulin. In: Wartofsky L, Van Nostrand D, eds. Thyroid Cancer: A Comprehensive Guide to Clinical Management. New York, NY: Springer; 2016:529-538.

74. Goldman JM, Line BR, Aamodt RL, Robbins J. Influence of triiodothyronine withdrawal time on ${ }^{131} \mathrm{I}$ uptake postthyroidectomy for thyroid cancer. J Clin Endocrinol Metab. 1980;50:734-739.

75. Choudhury PS, Gupta M. Differentiated thyroid cancer theranostics: radioiodine and beyond. Br J Radiol. 2018;91:20180136.

76. Van Nostrand D. Radioiodine refractory differentiated thyroid cancer: time to update the classifications. Thyroid. 2018;28:1083-1093.

77. Dietlein M, Scheidhauer K, Voth E, Theissen P, Schicha H. Fluorine-18 fluorodeoxyglucose positron emission tomography and iodine-131 whole-body scintigraphy in the follow-up of differentiated thyroid cancer. Eur J Nucl Med. 1997;24:1342-1348.

78. Miyamoto S, Kasagi K, Misaki T, Alam MS, Konishi J. Evaluation of technetium-99m-MIBI scintigraphy in metastatic differentiated thyroid carcinoma. J Nucl Med. 1997;38:352-356.

79. Qiu ZL, Xue YL, Song HJ, Luo QY. Comparison of the diagnostic and prognostic values of ${ }^{99 m}$ Tc-MDP-planar bone scintigraphy, ${ }^{131}$ I-SPECT/CT and ${ }^{18} \mathrm{~F}-\mathrm{FDG}-$ PET/CT for the detection of bone metastases from differentiated thyroid cancer. Nucl Med Commun. 2012;33:1232-1242.

80. de Geus-Oei LF, Oei HY, Hennemann G, Krenning EP. Sensitivity of ${ }^{123}$ I wholebody scan and thyroglobulin in the detection of metastases or recurrent differentiated thyroid cancer. Eur J Nucl Med Mol Imaging. 2002;29:768-774.

81. Santhanam P, Taieb D, Solnes L, Marashdeh W, Ladenson PW. Utility of I-124 PET/CT in identifying radioiodine avid lesions in differentiated thyroid cancer: a systematic review and meta-analysis. Clin Endocrinol (Oxf). 2017;86:645651.

82. Hsiao E, Huynh T, Mansberg R, Bautovich G, Roach P. Diagnostic I-123 scintigraphy to assess potential breast uptake of I-131 before radioiodine therapy in a postpartum woman with thyroid cancer. Clin Nucl Med. 2004;29:498-501. 
83. Tuttle RM, Leboeuf R, Robbins RJ, et al. Empiric radioactive iodine dosing regimens frequently exceed maximum tolerated activity levels in elderly patients with thyroid cancer. $J$ Nucl Med. 2006;47:1587-1591.

84. Strigari L, Konijnenberg M, Chiesa C, et al. The evidence base for the use of internal dosimetry in the clinical practice of molecular radiotherapy. Eur J Nucl Med Mol Imaging. 2014;41:1976-1988.

85. Klubo-Gwiezdzinska J, Van Nostrand D, Atkins F, et al. Efficacy of dosimetric versus empiric prescribed activity of ${ }^{131}$ I for therapy of differentiated thyroid cancer. J Clin Endocrinol Metab. 2011;96:3217-3225.

86. Deandreis D, Rubino C, Tala H, et al. Comparison of empiric versus wholebody/-blood clearance dosimetry-based approach to radioactive iodine treatment in patients with metastases from differentiated thyroid cancer. $\mathrm{J} \mathrm{Nucl}$ Med. 2017;58:717-722.

87. Flux GD, Verburg FA, Chiesa C, et al. Comparison of empiric versus dosimetryguided radioiodine therapy: the devil is in the details. J Nucl Med. 2017;58:862.

88. Tulchinsky M, Gross LJ. Comparison of empiric versus dosimetry-guided radioiodine therapy: the devil is in the details. J Nucl Med. 2017;58:863.

89. Van Nostrand D. Prescribed 'activity of ${ }^{131} \mathrm{I}$ therapy in differentiated thyroid cancer. J Nucl Med. 2017;58:697-699.

90. Verburg FA, Luster M, Giovanella L, et al. The "reset button" revisited: why high activity ${ }^{131} \mathrm{I}$ therapy of advanced differentiated thyroid cancer after dosimetry is advantageous for patients. Eur J Nucl Med Mol Imaging. 2017;44:915-917.

91. Benua RS, Cicale NR, Sonenberg M, Rawson RW. The relation of radioiodine dosimetry to results and complications in the treatment of metastatic thyroid cancer. Am J Roentgenol Radium Ther Nucl Med. 1962;87:171-182.

92. Leeper RD. The effect of 131 I therapy on survival of patients with metastatic papillary or follicular thyroid carcinoma. J Clin Endocrinol Metab. 1973;36: $1143-1152$.

93. Maxon HR. Quantitative radioiodine therapy in the treatment of differentiated thyroid cancer. Q J Nucl Med. 1999;43:313-323.

94. Silberstein EB, Alavi A, Balon HR, et al. The SNMMI practice guideline for therapy of thyroid disease with ${ }^{131}$ I 3.0. J Nucl Med. 2012;53:1633-1651.

95. Van Nostrand D, Neutze J, Atkins F. Side effects of "rational dose" iodine-131 therapy for metastatic well-differentiated thyroid carcinoma. J Nucl Med. 1986;27: 1519-1527.

96. Bushnell DL, Boles MA, Kaufman GE, Wadas MA, Barnes WE. Complications, sequela and dosimetry of iodine-131 therapy for thyroid carcinoma. J Nucl Med. 1992;33:2214-2221.

97. Lassmann M, Hanscheid H, Chiesa C, et al. EANM Dosimetry Committee series on standard operational procedures for pre-therapeutic dosimetry I: blood and bone marrow dosimetry in differentiated thyroid cancer therapy. Eur J Nucl Med Mol Imaging. 2008;35:1405-1412.

98. Gulec SA, Kuker RA, Goryawala M, et al. ${ }^{124}$ I PET/CT in patients with differentiated thyroid cancer: clinical and quantitative image analysis. Thyroid. 2016;26:441-448

99. Lassmann M, Reiners C, Luster M. Dosimetry and thyroid cancer: the individual dosage of radioiodine. Endocr Relat Cancer. 2010;17:R161-R172.

100. Maxon HR, 3rd, Englaro EE, Thomas SR, et al. Radioiodine-131 therapy for well-differentiated thyroid cancer-a quantitative radiation dosimetric approach: outcome and validation in 85 patients. J Nucl Med. 1992;33:1132-1136.

101. Sgouros G, Kolbert KS, Sheikh A, et al. Patient-specific dosimetry for ${ }^{131} \mathrm{I}$ thyroid cancer therapy using ${ }^{124}$ I PET and 3-dimensional-internal dosimetry (3D-ID) software. J Nucl Med. 2004;45:1366-1372.

102. Wierts R, Brans B, Havekes B, et al. Dose-response relationship in differentiated thyroid cancer patients undergoing radioiodine treatment assessed by means of ${ }^{124}$ I PET/CT. J Nucl Med. 2016;57:1027-1032.

103. Maxon HR, Thomas SR, Hertzberg VS, et al. Relation between effective radiation dose and outcome of radioiodine therapy for thyroid cancer. $N$ Engl J Med. 1983;309:937-941.

104. Jentzen W, Freudenberg L, Eising EG, Sonnenschein W, Knust J, Bockisch A. Optimized ${ }^{124}$ I PET dosimetry protocol for radioiodine therapy of differentiated thyroid cancer. J Nucl Med. 2008;49:1017-1023.

105. Schneider DF, Ojomo KA, Chen H, Sippel RS. Remnant uptake as a postoperative oncologic quality indicator. Thyroid. 2013;23:1269-1276.

106. Cherk MH, Kalff V, Yap KS, Bailey M, Topliss D, Kelly MJ. Incidence of radiation thyroiditis and thyroid remnant ablation success rates following 1110 $\mathrm{MBq}(30 \mathrm{mCi})$ and $3700 \mathrm{MBq}(100 \mathrm{mCi})$ post-surgical ${ }^{131} \mathrm{I}$ ablation therapy for differentiated thyroid carcinoma. Clin Endocrinol (Oxf). 2008;69:957-962.

107. Verkooijen RB, Rietbergen D, Smit JW, Romijn JA, Stokkel MP. A new functional parameter measured at the time of ablation that can be used to predict differentiated thyroid cancer recurrence during follow-up. Eur J Endocrinol. 2007;156:41-47.

108. Burmeister LA, du Cret RP, Mariash CN. Local reactions to radioiodine in the treatment of thyroid cancer. Am J Med. 1991;90:217-222.
109. Randolph GW, Daniels GH. Radioactive iodine lobe ablation as an alternative to completion thyroidectomy for follicular carcinoma of the thyroid. Thyroid. 2002;12:989-996.

110. Denlinger CS, Sanft T, Baker KS, et al. Survivorship, version 2.2017, NCCN Clinical Practice Guidelines in Oncology. J Natl Compr Canc Netw. 2017;15: $1140-1163$

111. Nabhan F, Ringel MD. Thyroid nodules and cancer management guidelines: comparisons and controversies. Endocr Relat Cancer. 2017;24:R13-R26.

112. Perros P, Boelaert K, Colley S, et al. Guidelines for the management of thyroid cancer. Clin Endocrinol (Oxf). 2014;81(suppl 1):1-122.

113. Haddad RI, Lydiatt WM, Ball DW, et al. Anaplastic thyroid carcinoma, version 2.2015. J Natl Compr Canc Netw. 2015;13:1140-1150.

114. Smallridge RC, Ain KB, Asa SL, et al. American Thyroid Association guidelines for management of patients with anaplastic thyroid cancer. Thyroid. 2012;22:1104-1139.

115. Meijer JA, Bakker LE, Valk GD, et al. Radioactive iodine in the treatment of medullary thyroid carcinoma: a controlled multicenter study. Eur J Endocrinol. 2013; 168:779-786.

116. Wells SA Jr, Asa SL, Dralle H, et al. Revised American Thyroid Association guidelines for the management of medullary thyroid carcinoma. Thyroid. 2015;25:567-610.

117. Tohidi M, Pourbehi G, Bahmanyar M, Eghbali SS, Kalantar Hormozi M, Nabipour I. Mixed medullary-follicular carcinoma of the thyroid. Case Rep Endocrinol. 2013;2013:571692.

118. Papotti M, Volante M, Komminoth P, Sobrinho-Simoes M, Bussolati G. Thyroid carcinomas with mixed follicular and C-cell differentiation patterns. Semin Diagn Pathol. 2000;17:109-119.

119. Momesso DP, Tuttle RM. Update on differentiated thyroid cancer staging. Endocrinol Metab Clin North Am. 2014;43:401-421.

120. Kloos RT. Approach to the patient with a positive serum thyroglobulin and a negative radioiodine scan after initial therapy for differentiated thyroid cancer. J Clin Endocrinol Metab. 2008;93:1519-1525.

121. Wang W, Larson SM, Tuttle RM, et al. Resistance of [18f]-fluorodeoxyglucoseavid metastatic thyroid cancer lesions to treatment with high-dose radioactive iodine. Thyroid. 2001;11:1169-1175.

122. Deandreis D, Al Ghuzlan A, Leboulleux S, et al. Do histological, immunohistochemical, and metabolic (radioiodine and fluorodeoxyglucose uptakes) patterns of metastatic thyroid cancer correlate with patient outcome? Endocr Relat Cancer. 2011;18:159-169.

123. Schmohl KA, Dolp P, Schug C, et al. Reintroducing the sodium-iodide symporter to anaplastic thyroid carcinoma. Thyroid. 2017;27:1534-1543.

124. Hassan A, Riaz S, Bashir H, Nawaz MK, Hussain R. Can the American Thyroid Association risk of recurrence predict radioiodine refractory disease in differentiated thyroid cancer? Eur Thyroid J. 2016;5:261-267.

125. Liu M, Chai L, Luo Q, et al. ${ }^{99 \mathrm{~m}} \mathrm{Tc}$-pertechnetate-avid metastases from differentiated thyroid cancer are prone to benefit from ${ }^{131} \mathrm{I}$ therapy: a prospective observational study. Medicine (Baltimore). 2017;96:e7631.

126. Aydin F, Sipahi M, Budak ES, et al. Role of Tc-99m pertechnetate for remnant scintigraphy, post-thyroidectomy, and serum thyroglobulin and antithyroglobulin antibody levels in the patients with differentiated thyroid cancer. Ann Nucl Med. 2016;30:60-67.

127. Lou K, Gu Y, Hu Y, Wang S, Shi H. Technetium-99m-pertechnetate whole-body SPET/CT scan in thyroidectomized differentiated thyroid cancer patients is a useful imaging modality in detecting remnant thyroid tissue, nodal and distant metastases before (131)I therapy: a study of 416 patients. Hell J Nucl Med. 2018;21:121-124.

128. Chantadisai M, Kingpetch K. Usefulness of ${ }^{99 \mathrm{~m}}$ Tc-pertechnetate whole body scan with neck and chest SPECT/CT for detection of post-surgical thyroid remnant and metastasis in differentiated thyroid cancer patients. Ann Nucl Med. 2014;28:674-682.

129. Russell JR, Stabin MG, Sparks RB, Watson E. Radiation absorbed dose to the embryo/fetus from radiopharmaceuticals. Health Phys. 1997;73:756-769.

130. Demir Ö, Köse N, Özkan E, Ünlütürk U, Aras G, Erdoğan MF. Clinical significance of thyroid incidentalomas identified by ${ }^{18} \mathrm{~F}-\mathrm{FDG}$ PET/CT: correlation of ultrasonograpy findings with cytology results. Nucl Med Commun. 2016;37:715-720.

131. Şencan Eren M, Özdoğan Ö, Gedik A, et al. The incidence of ${ }^{18}$ F-FDG PET/CT thyroid incidentalomas and the prevalence of malignancy: a prospective study. Turk J Med Sci. 2016;46:840-847.

132. Piccardo A, Puntoni M, Treglia G, et al. Thyroid nodules with indeterminate cytology: prospective comparison between ${ }^{18} \mathrm{~F}-\mathrm{FDG}-\mathrm{PET} / \mathrm{CT}$, multiparametric neck ultrasonography, ${ }^{99 \mathrm{~m} T c-M I B I}$ scintigraphy and histology. Eur J Endocrinol. 2016;174:693-703. 
133. Wiebel JL, Esfandiari NH, Papaleontiou M, Worden FP, Haymart MR. Evaluating positron emission tomography use in differentiated thyroid cancer. Thyroid. 2015;25:1026-1032.

134. Feine U, Lietzenmayer R, Hanke J-P, Held J, Wöhrle H, Müller-Schauenburg W. Fluorine-18-FDG and iodine-131-iodide uptake in thyroid cancer. $\mathrm{J} \mathrm{Nucl} \mathrm{Med}$. 1996;37:1468-1472.

135. Leide-Svegborn S, Ahlgren L, Johansson L, Mattsson S. Excretion of radionuclides in human breast milk after nuclear medicine examinations: biokinetic and dosimetric data and recommendations on breastfeeding interruption. Eur J Nucl Med Mol Imaging. 2016;43:808-821.

136. Kim SJ, Lee SW, Jeong SY, Pak K, Kim K. Diagnostic performance of technetium-99m methoxy-isobutyl-isonitrile for differentiation of malignant thyroid nodules: a systematic review and meta-analysis. Thyroid. 2018;28:1339-1348.

137. Jain D. Technetium-99m labeled myocardial perfusion imaging agents. Semin Nucl Med. 1999;29:221-236.

138. Wartofsky L. rhTSH-Stimulated Thyroglobulin Study Group. Management of low-risk well-differentiated thyroid cancer based only on thyroglobulin measurement after recombinant human thyrotropin. Thyroid. 2002;12:583-590.

139. Middendorp M, Selkinski I, Happel C, Kranert WT, Grunwald F. Comparison of positron emission tomography with $\left[{ }^{18} \mathrm{~F}\right] \mathrm{FDG}$ and $\left[{ }^{68} \mathrm{Ga}\right]$ DOTATOC in recurrent differentiated thyroid cancer: preliminary data. $Q \mathrm{~J} \mathrm{Nucl} \mathrm{Med} \mathrm{Mol}$ Imaging. 2010;54:76-83.
140. Vrachimis A, Stegger L, Wenning C, et al. [ ${ }^{68} \mathrm{Ga}$ ]DOTATATE PET/MRI and $\left[{ }^{18} \mathrm{~F}\right]$ FDG PET/CT are complementary and superior to diffusion-weighted MR imaging for radioactive-iodine-refractory differentiated thyroid cancer. Eur $J$ Nucl Med Mol Imaging. 2016;43:1765-1772.

141. Binse I, Poeppel TD, Ruhlmann M, et al. ${ }^{68}$ Ga-DOTATOC PET/CT in patients with iodine- and ${ }^{18}$ F-FDG-negative differentiated thyroid carcinoma and elevated serum thyroglobulin. J Nucl Med. 2016;57:1512-1517.

142. Durante C, Haddy N, Baudin E, et al. Long-term outcome of 444 patients with distant metastases from papillary and follicular thyroid carcinoma: benefits and limits of radioiodine therapy. J Clin Endocrinol Metab. 2006;91: 2892-2899.

143. Czepczyński R, Matysiak-Grzes M, Gryczynska M, et al. Peptide receptor radionuclide therapy of differentiated thyroid cancer: efficacy and toxicity. Arch Immunol Ther Exp (Warsz). 2015;63:147-154.

144. Versari A, Sollini M, Frasoldati A, et al. Differentiated thyroid cancer: a new perspective with radiolabeled somatostatin analogues for imaging and treatment of patients. Thyroid. 2014;24:715-726.

145. Tuttle RM, Ahuja S, Avram AM, et al. Controversies, consensus, and collaboration in the use of (131)I therapy in differentiated thyroid cancer: a joint statement from the American Thyroid Association, the European Association of Nuclear Medicine, the Society of Nuclear Medicine and Molecular Imaging, and the European Thyroid Association. Thyroid. 2019;29:461-470. 